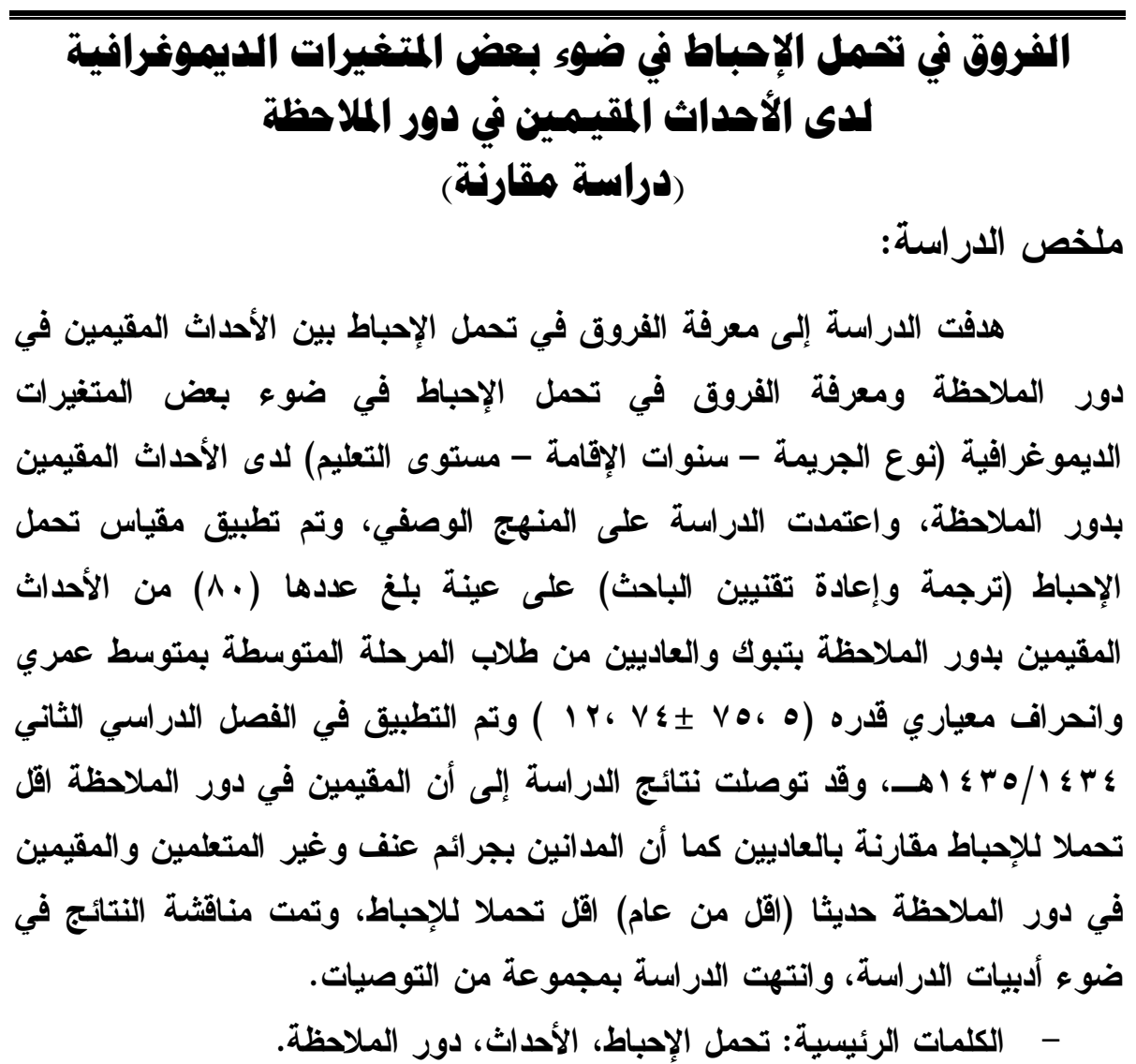

The current study aimed at exploring frustration tolerance among delinquents in juvenile institutions and investigating differences in frustration tolerance according to some demographic variables (crime type- years of being in the institution- educational level). The study utilized the descriptive method and frustration tolerance scale was administered on 80 delinquents and normal adolescents in the middle school. The results of the study showed that delinquents in juvenile institutions have low frustration tolerance than the normal. Also, the results indicated that delinquents accused of violence crimes, non-educable and those staying in the juvenile institutions have low frustration tolerance as well. The results were analyzed in the light of the literature and some recommendations were suggested. 


$$
\text { مقدمة ومدخل الارسة: }
$$

تعل مشكلة الأحداث الجاتحين من المشكلات النفسية والاجتماعية التي تواجه واجها

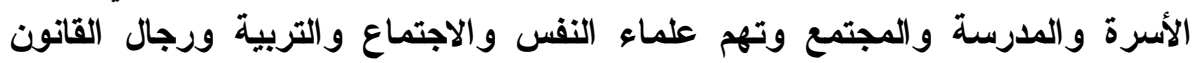

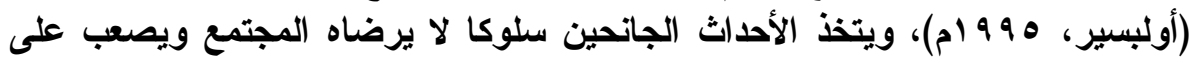

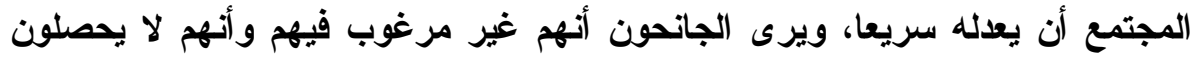

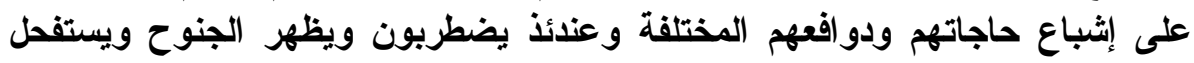

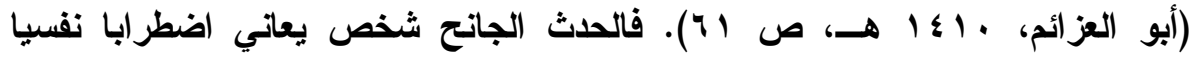

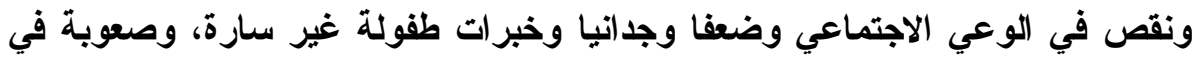

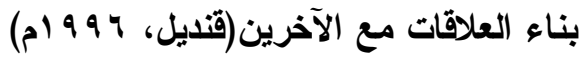

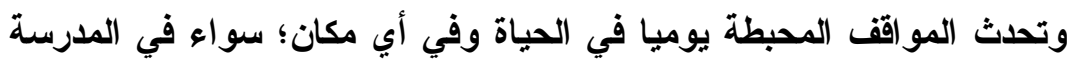

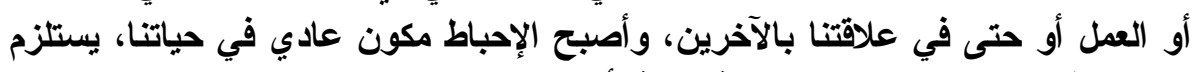

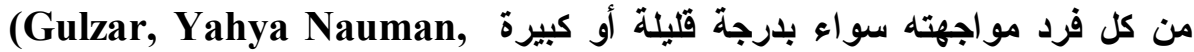

Mir \& Mujahid, 2012)

ويرى علماء النفس أن الإحباط حالة انفعالية تظهر عندما تنتخل عقبة ما في

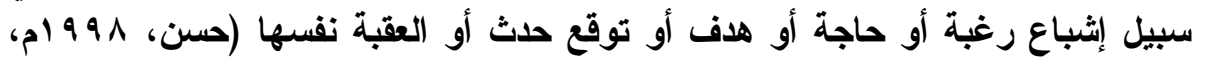

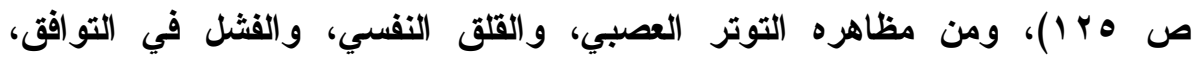

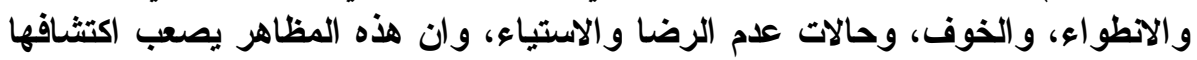

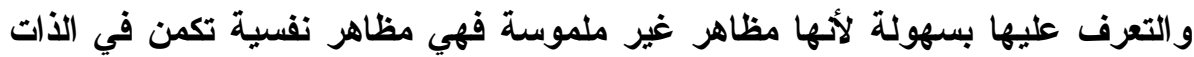

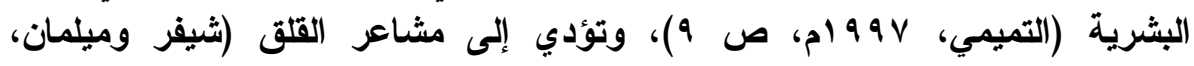

ويعني تحمل الإحباط Frustration Tolerance قدرة الفرد على احتمال

الإحباط، واحتمال الثدائد دون أن يلجأ إلى أساليب ملتوية، أو غير ملائمة لحل مشكلاته

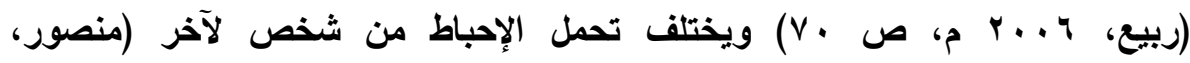

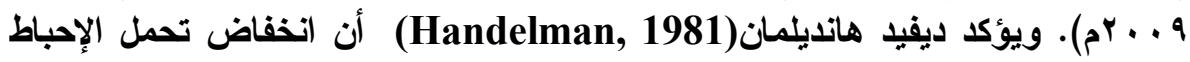

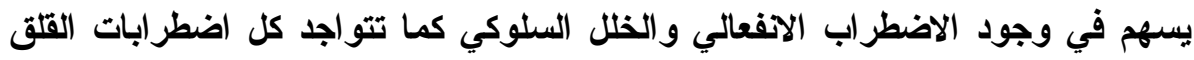

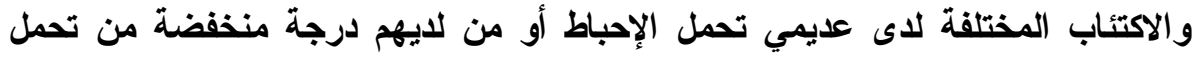

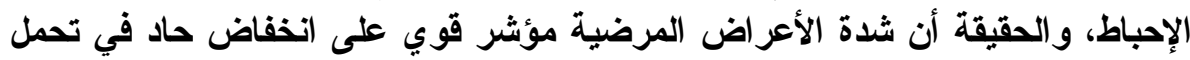

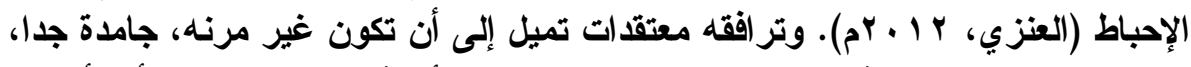

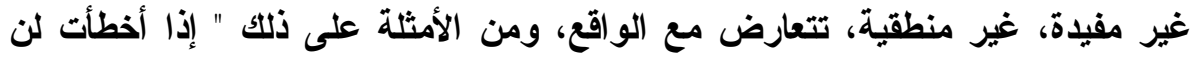

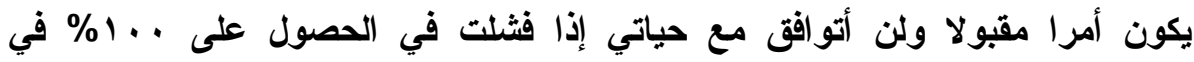

امتحاني " (Katherinehenning, 2014). 


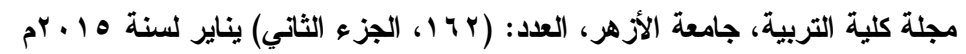

(Anitei, Chraif \& Liliana, كما أظهرت دراسة أنيتي وكريف وليليانا (2013 أن تحمل الإحباط يرتبط بالغضب و السلوك العدو واني لدى الأطفال والمراهقين في

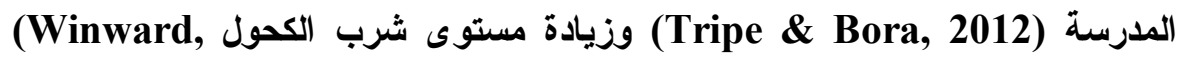
والتدخين Bekman, Hanson, Lejuez \& Brown, 2014) (Sirota, Rohsenow, Dolan, Martin \& Kahler, 2012) المعالجين من شرب الكحول (Baras, Muller, Gallhofer \& Netter, 2013) والقيادة بعدوانية وبطريقة محفوفة بالمخاطر (Beck, Ali \& Daughters, 2014) و إدمان الاتترنت Ko, Yen, Yen, Chen \& Wang, Internet addiction (2008، والنجاح المهني (Makarevich, 1986) ونتائج التحصيل الدراسي (Pouyamnesh \& Firoozeh, 2013)

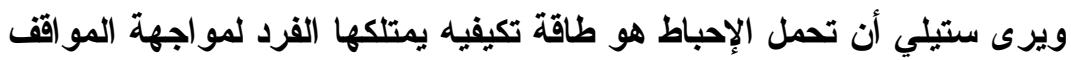

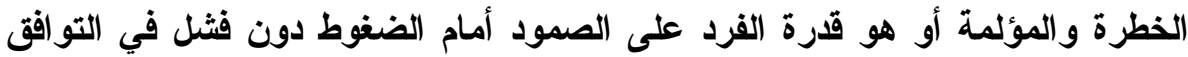

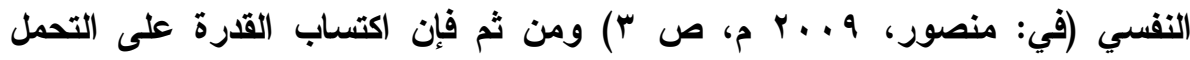

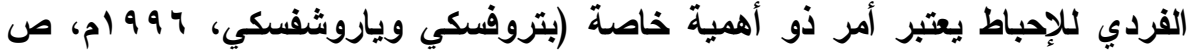

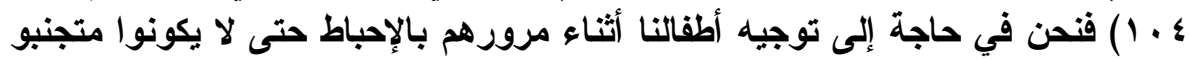

الصر اع وهم راثدين (Nair, 2014).

ولذا توجهت الدارسة الحالية لاراسة الفرق في تحمل الإحباط بين المقيمين في

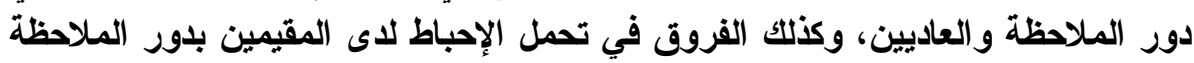
في ضوء بعض المتغيرات الديموغرافية (نوع الجريمة - سنوات الإناطية الإقامة - مستوى (التعليم).

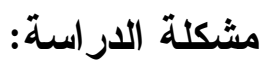

من المعروف أن ظاهرة جناح الأحداث ليست مشكلة جديدة تعاني منها

المجتمعات الحديثة أو نشأت نتيجة التطور الحديث في المجتمعات، ولكنها مشكلة قديمة

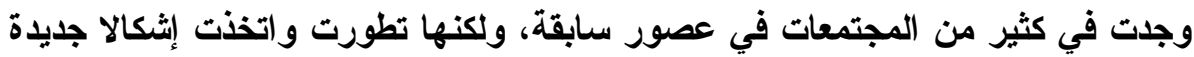

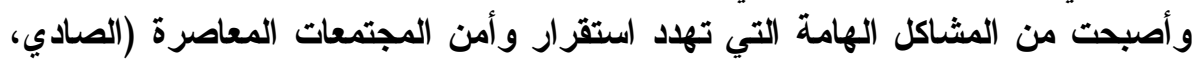

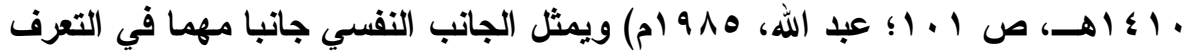

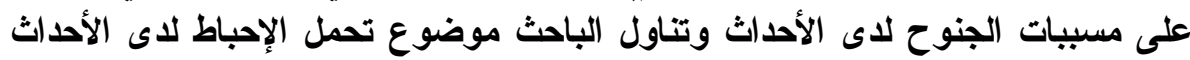

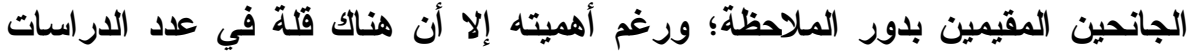

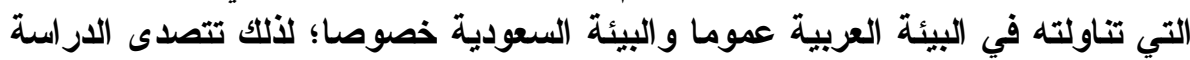
الحالية للإجابة على الأسئلة التالية. 
- هل هناك فروق في تحمل الإحباط بين الأحداث المقيمين في دور الملاحظة والعاديين؟

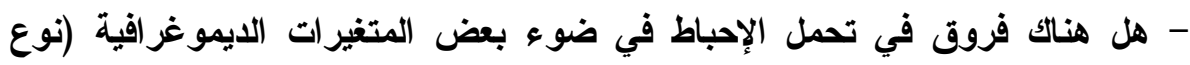
الجريمة - سنوات الإقامة - مستوى التعليم) لاى الأحداث المقيمين بدور الملاحظة المباء

$$
\text { أهداف الار اسة: تهدف الاراسة إلى: }
$$

- معرفة الفروق في تحمل الإحباط بين الأحداث المقيمين في دور الملاحظة والعاديين.

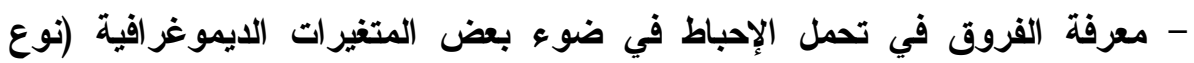

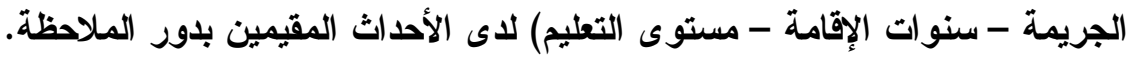

$$
\text { أهمية الدر (سنة: }
$$

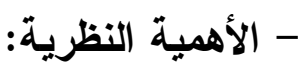

- من حيث الموضوع: الإضافة العلمية التي ستضيفها الاراسة إلى التراث العلمي في

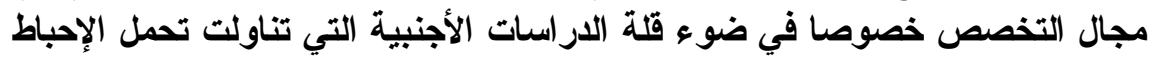

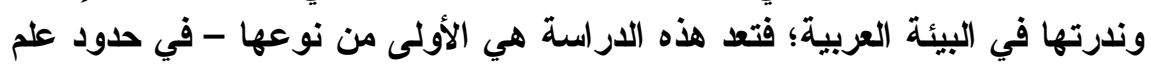

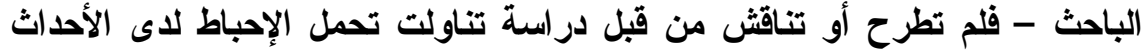
الجانحين المقيمين في دور الملاحظة.

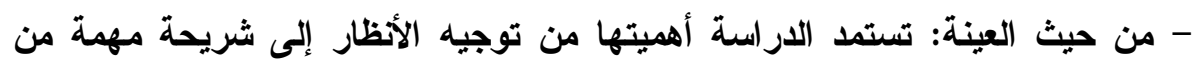

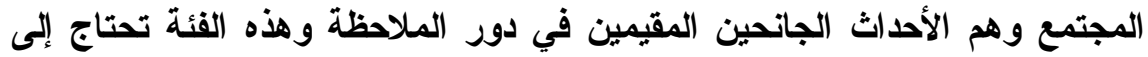

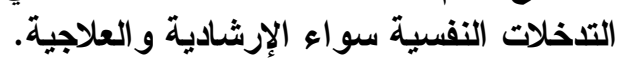

- من حيث الأدوات: توفر الاراسة مقياس لتحمل الإحباط يصلح للتطبيق على عينة الار اسة وتتو افر فيه الشروط السيكومترية ومقنن على البيئة السعودية.

- الأهمية التطبيقية:

- الاستفادة من نتائج الاراسة في تصميم وتطبيق برامج إرشادية لزيادة تحمل الإحباط لاى الأحداث منخفضي تحمل الإحباط وانعكاس ذلك على صحتهم النفسية.

$$
\text { تتحدد حدود الاراسة فيما يلي: }
$$

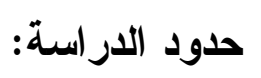

- الحدود الموضوعية: تتحدد بالمتغيرات التالية: تحمل الإحباط وبعض المتغيرات الايموغر افية (نوع الجريمة - سنوات الإقامة - مستوى التعليم). 


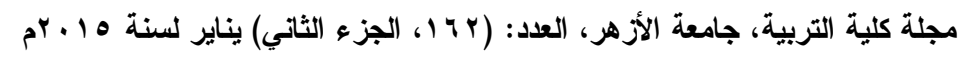

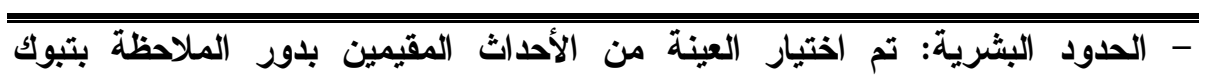

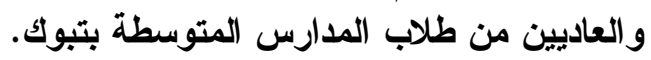

- الحدود المكانية والزمانية: طبقت الدراسة بمدينة تبوك في الفصل الارسي الثاني . $1 \leqslant \mu 0 / 1 \leqslant r \leqslant$

مصطلحات الار اسة:

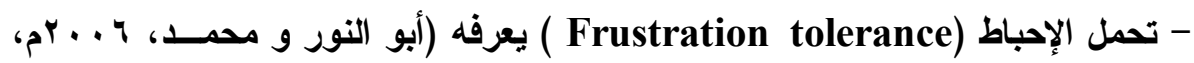

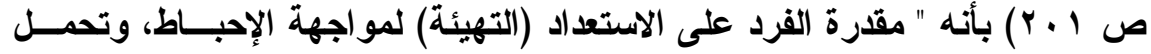

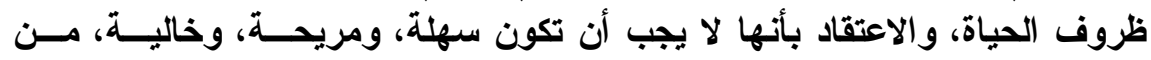

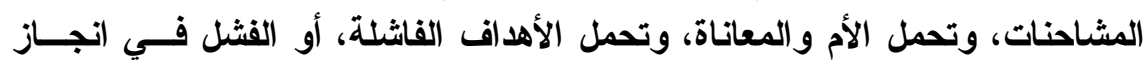

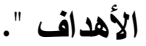

جنوح الأحداث: يعرف الجنوح Delinquency بأنه " المخالفات والجنح المرتكبة

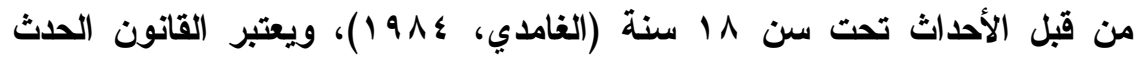

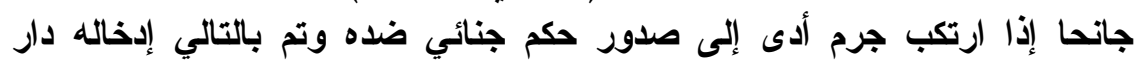

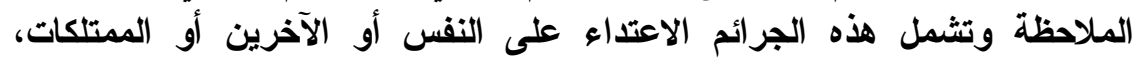

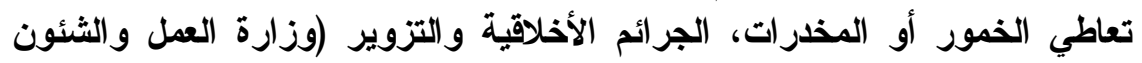

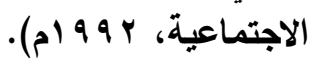

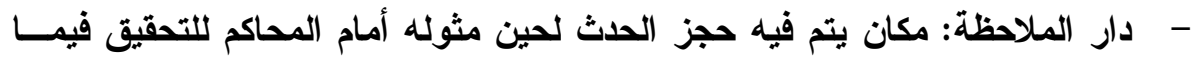

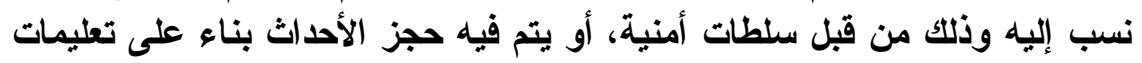

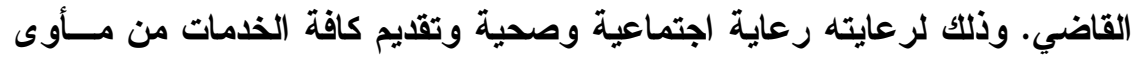

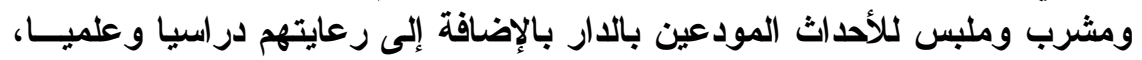

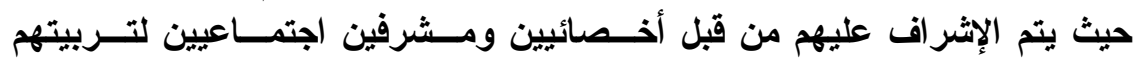

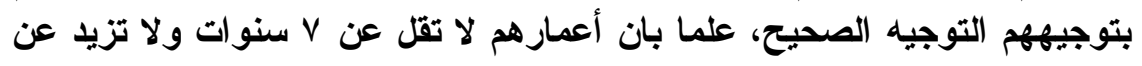

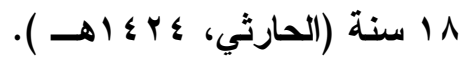

$$
\text { جناح الأحداث الدراثة: }
$$

يمكن تعريف جناح الأحداث حسب المنظور النفسي بأنه "سلوك غير اجتماعي

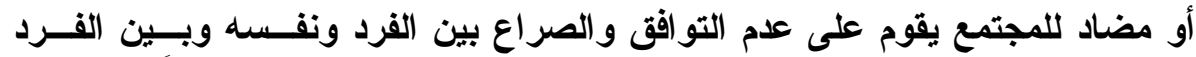

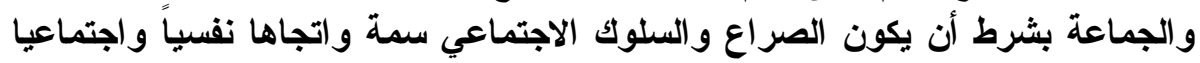

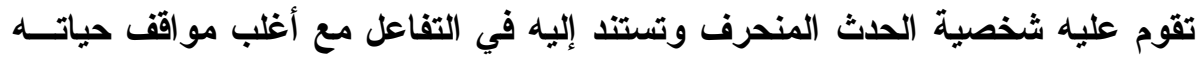




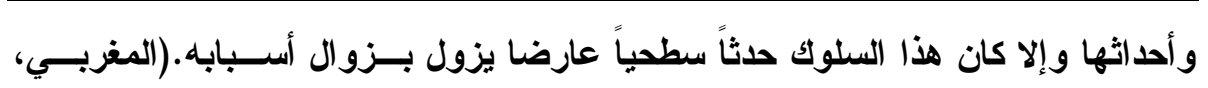

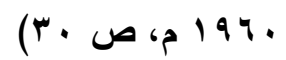

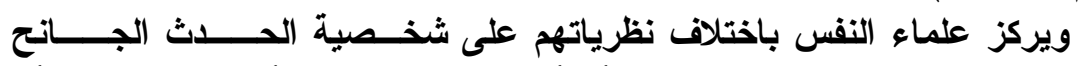

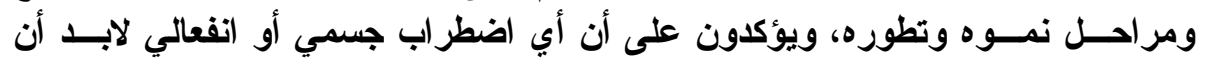

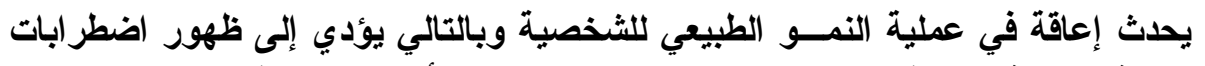

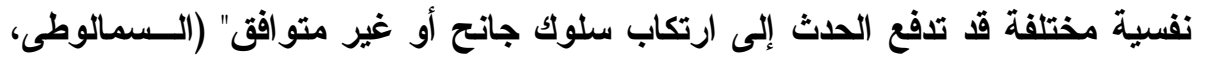

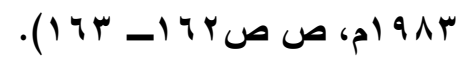

وترى السلوكية أن الجنوح استجابة غير موجهة للقلق الناتج عن استــتمرار

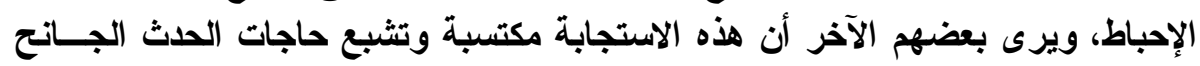

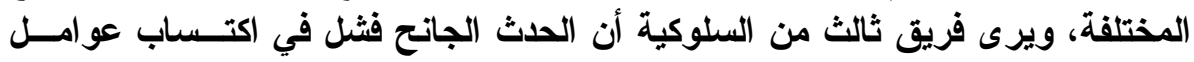

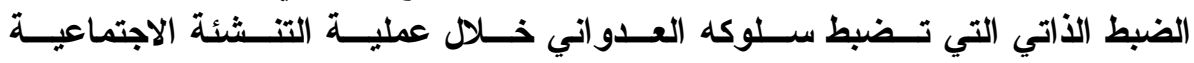
(Corey, 2005)

أما المعرفية، فيرى أليس أن الجنوح يعود إلى الأفكار اللاعقلانية التي يتبناها

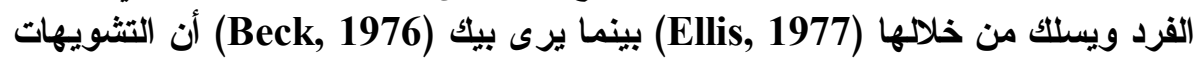

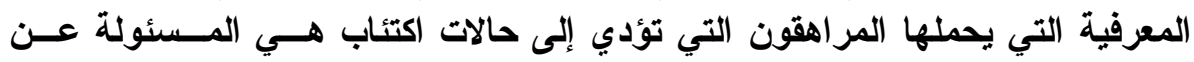

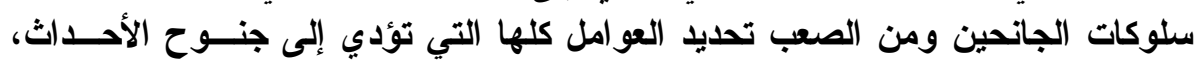

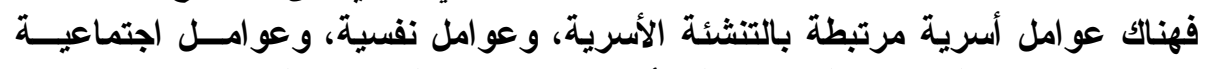

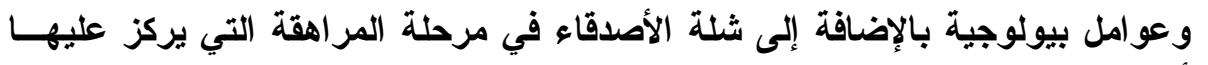

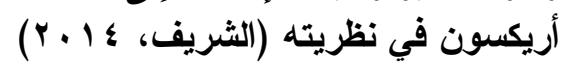
العوامل المؤثرة في اتحر اف الحدث:

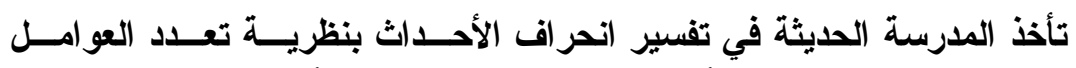

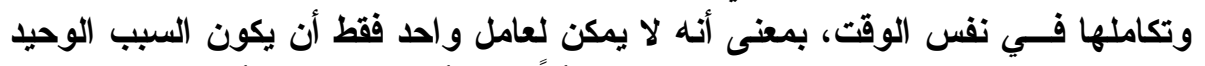

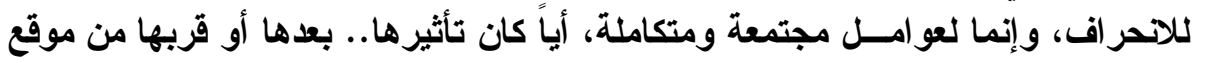

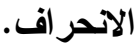

ولهذا توصي الهيئات العلمية المعنية بالبحث عن أسباب الاحمر اف أو الإجرام

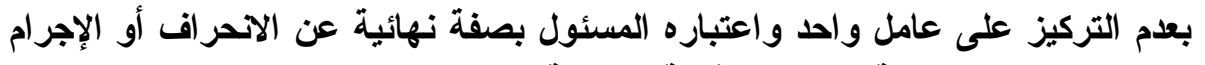

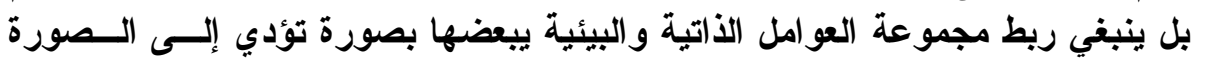

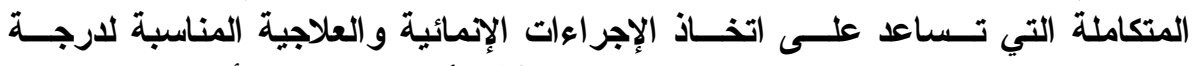

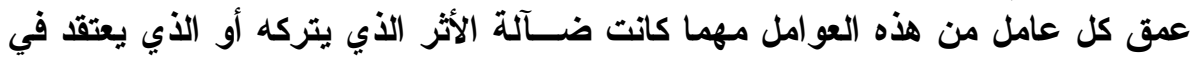
أنه ضعيف إلى حد كبير كعامل من عوامل الاتحر اف و الإجرام (حسن، ؛ 9 و ام). 


\section{تحمل الإحباط:}

يعتبر ميكارفيتش (Makarevich, 1986) تحمل الإحباط سمة شخصية هامه

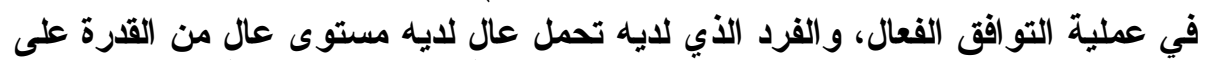
التو افق و التعامل مع ضغوط الحياة، بينما يعرفه كازرينًهنج "( , (Katherinehenning)

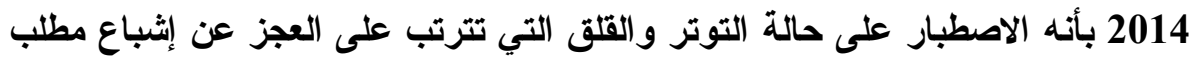

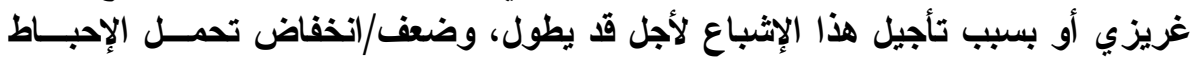
Low frustration tolerance (LFT)

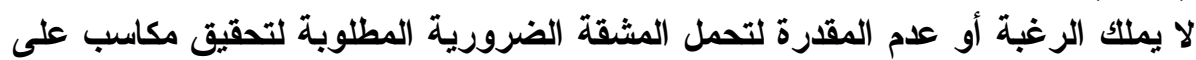

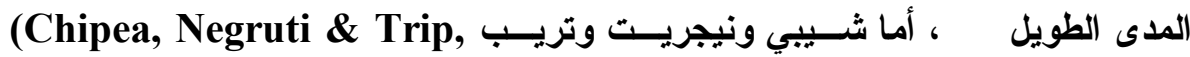

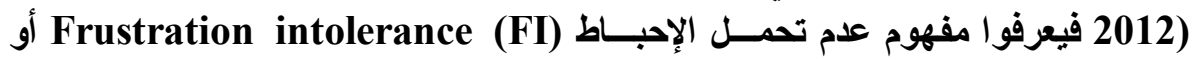

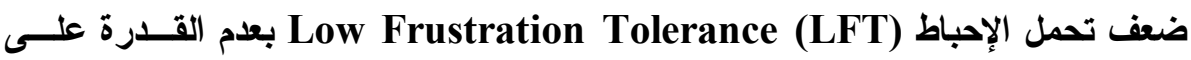
تحمل الواقع الأي يختلف عن توقعاتنا بتحقيق مطالبنا لحياة مثالية ومريحة

النظريات المفسرة لتحمل لإحباط: نظرية التحليل النفسي.

يقسم سيجموند فرويد الثخصية إلى ثلاثة أنظمة (ألهو، ألانا، الأنا الأعلى)

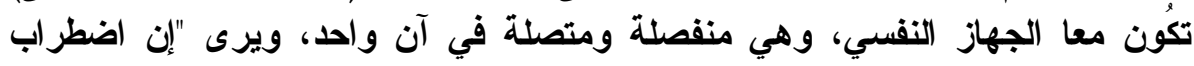

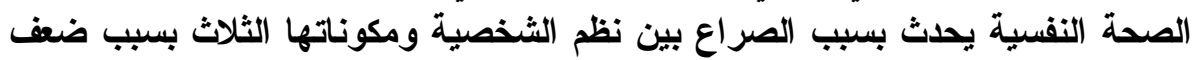
تحمل (الأنا) وعدم قدرته على التوفيق أو الوصول إلى حل للصر اع الذي الذي يحدث بين هذانه النظم ومطالب الواقع.

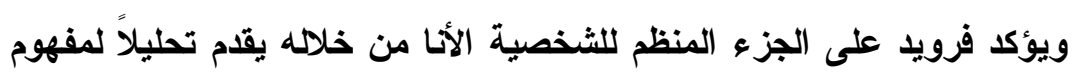

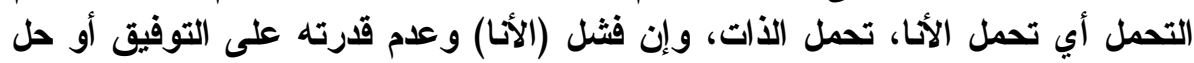

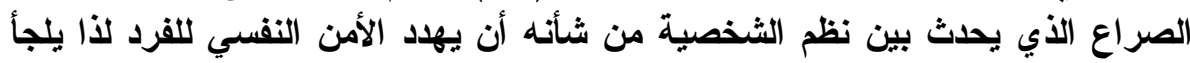

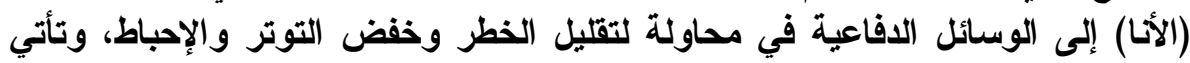

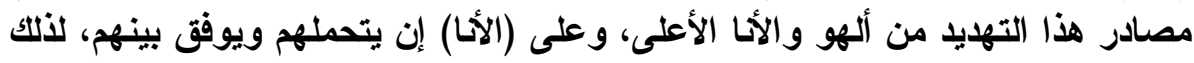

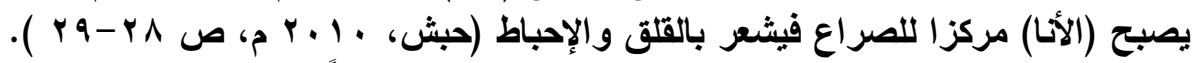

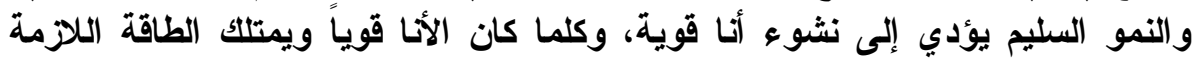

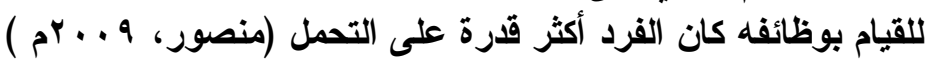




$$
\text { نظرية الإحباط - العدوان. }
$$

من العلماء النفسيين الأوائل الأي قدموا نظرية الإحباط - العدوان " دولارد Dollarde Sears

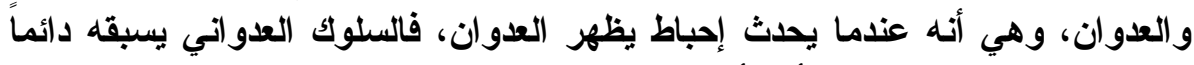

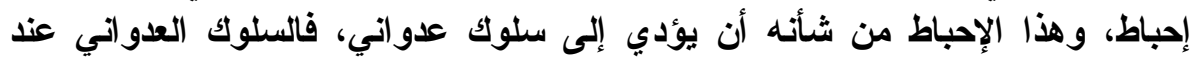

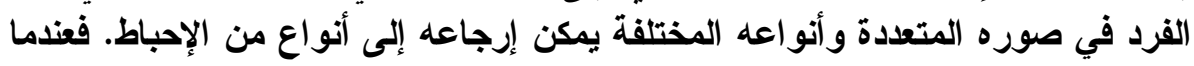

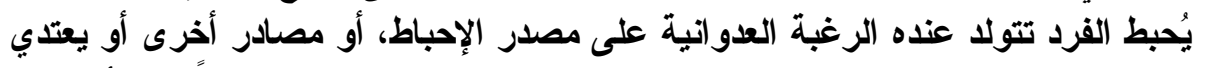

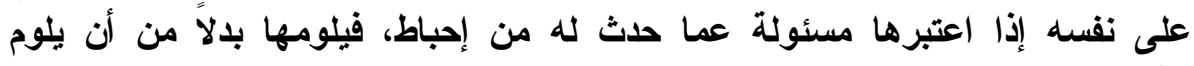

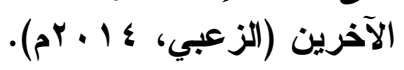

ولقد توصل رواد هذه النظرية إلى بعض الاستنتاجات من دراستهم عن العلاقة العابة بين الإحباط والعدوان والتي يمكن اعتبارها بمثابة الأسس النفسية المحددة لهذه لهذه العلاقة: أ- تختلف شدة الرغبة في السلوك العدواني باختلاف كمية الإحباط الذي يواجهه الفرد.

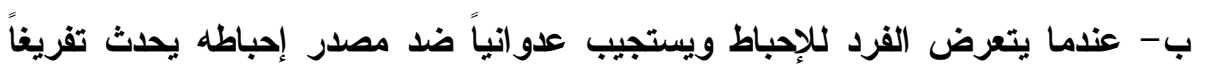

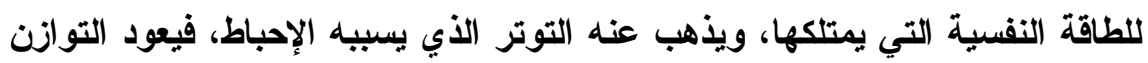
الداخلي للقرد.

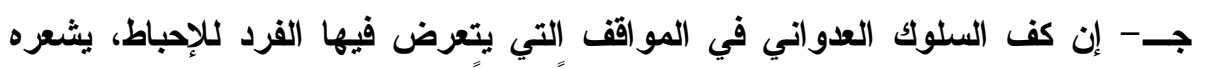

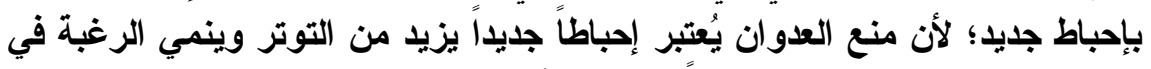

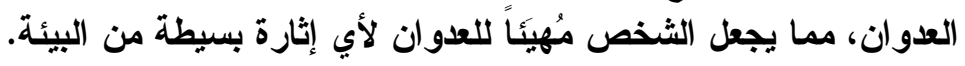

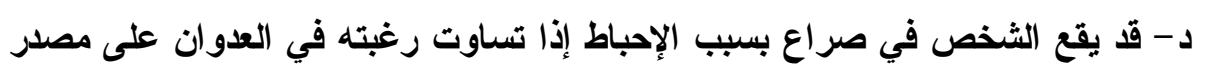

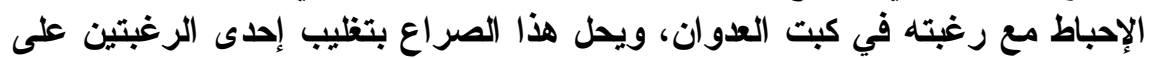

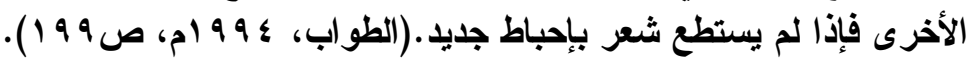

ويتفق معظم العاملين في مجال الصحة النفسية على أن الإحباط يؤدي إلى فئى

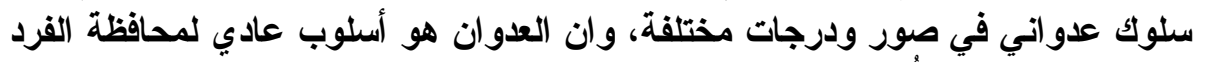

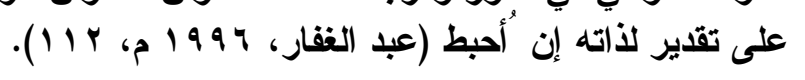

ويختلف الأفراد فيما بينهم في مدى تحملهم لما يلاقونه من إحباط، وتعتمد

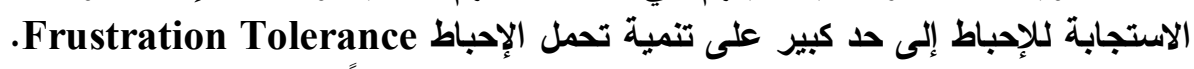

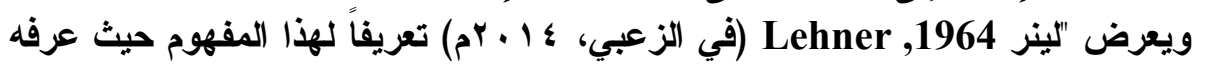

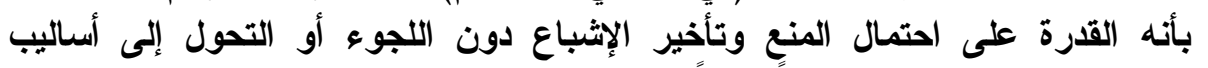

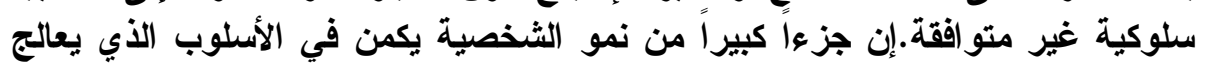




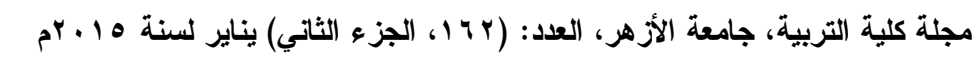

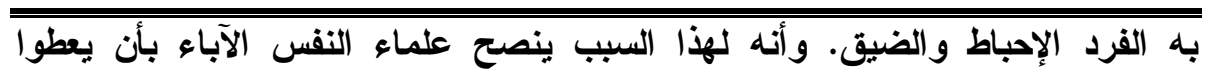

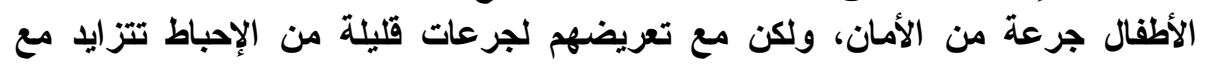

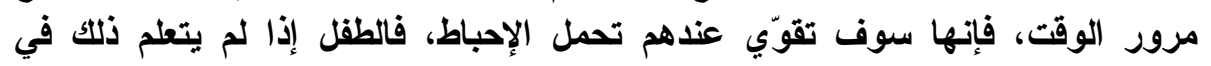
المواقف البسيطة فإنه سوف ينزعج بشدة عندم عندما يحدث لله إحباط شديد وتكون النتائج

نظرية التعلم:

حاول ابرام امسل Abram Amsel تحديد وتطوير مفهوم الإحباط في تطرية

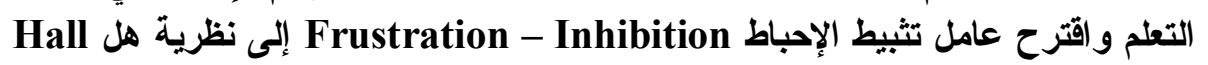

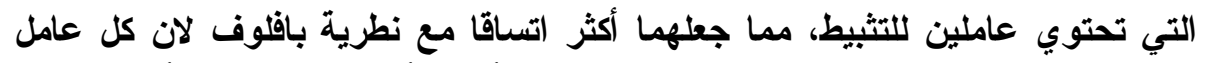

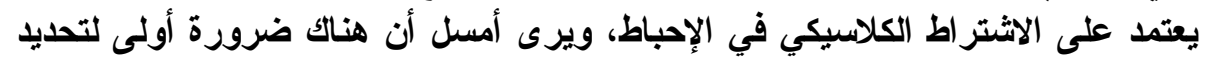

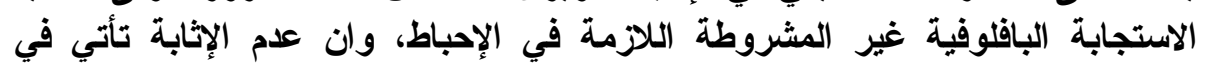

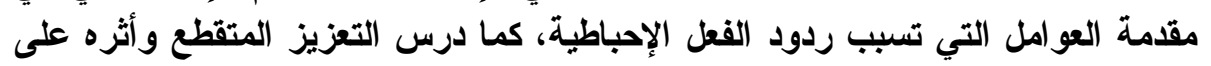

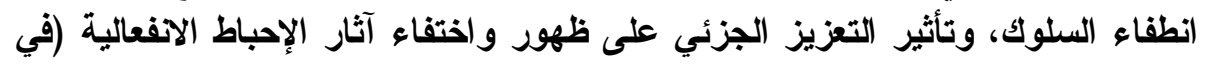

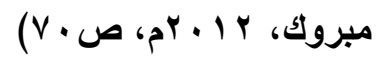

نظرية روزنزفايغ للإحباط:

عرف روزنزفايغ Rosenzweig الإحباط بأنه" يحدث في كل مرة يتعرض فيها

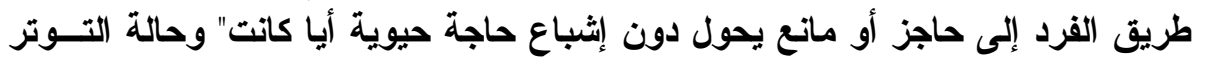

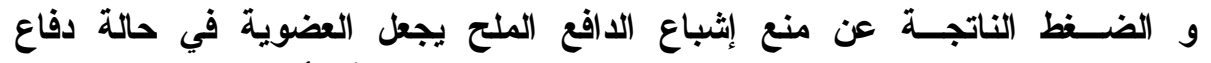

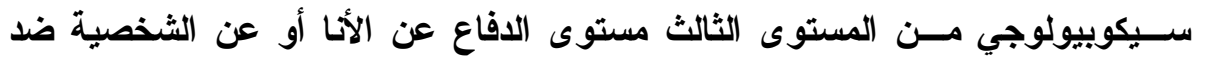

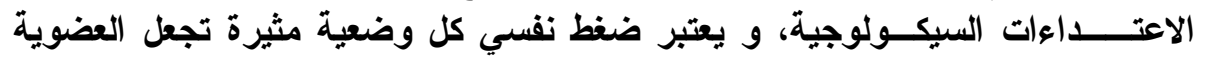

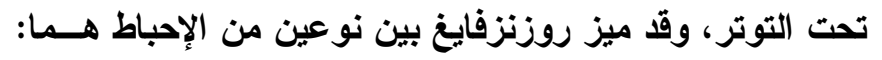

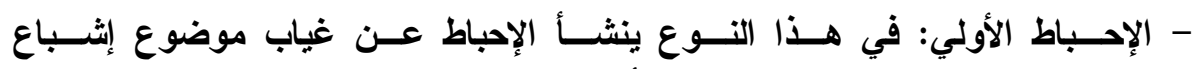

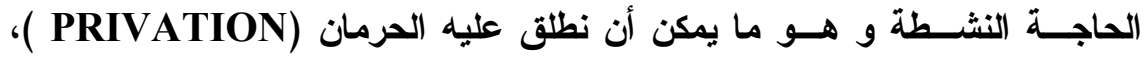
مثل شخص جائع و ليس لايه و أكـلــل

- الإحباط الثانوي: في هذا النوع ينشأ الإحباط عن وجود عائق دون إثباع الحاجة

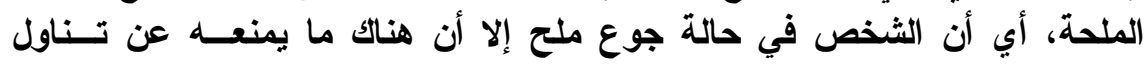
الطعسام. و الإحباط الثانوي وحده ينطبق عليه التعريف السابق لان لمفهوم الإحباط

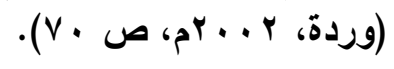




$$
\text { النظرية المعرفية - السلوكية: }
$$

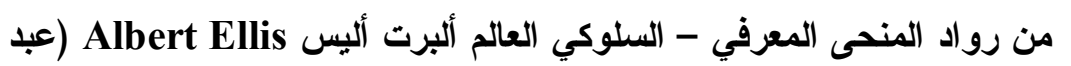

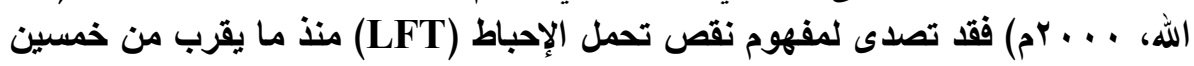

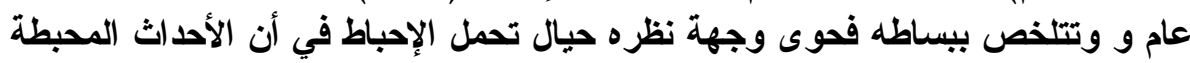

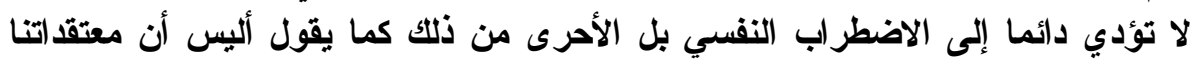

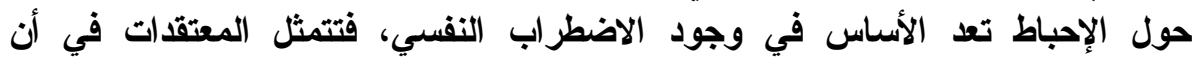

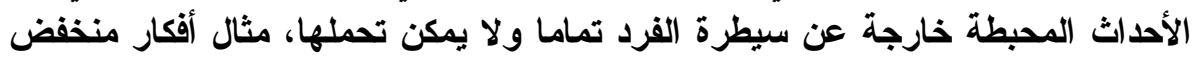

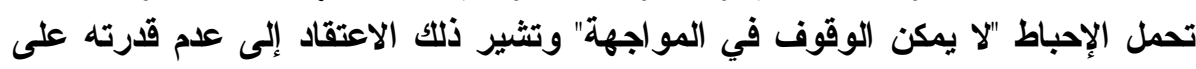

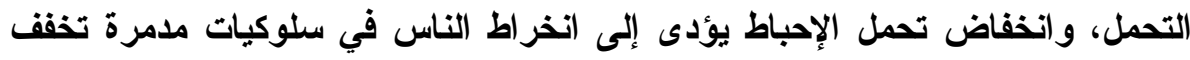

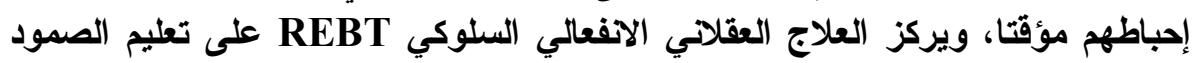
في مواجهة الإحباط والأي يسير جنبا إلى جنب مع تحقيق مكاسب الانعي على المدى الطويل .(Lackey, 2014)

وبرزت نظرية ألبرت أليس للتركيز ليس فقط على تهايدات تقدير الذات

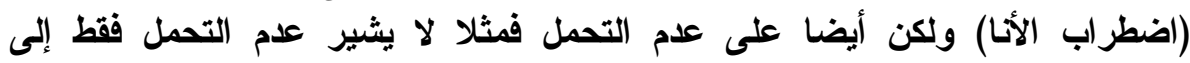

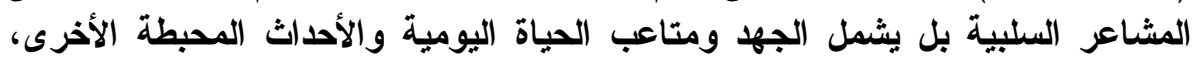

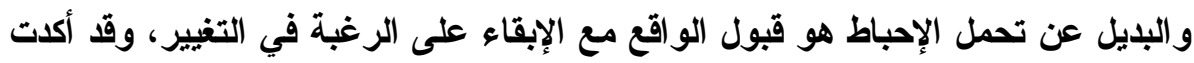

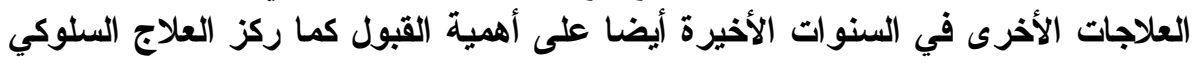

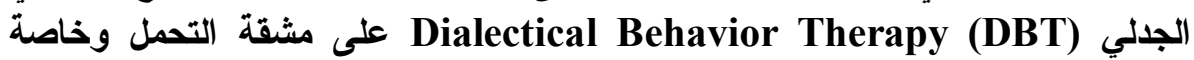
فيما يتعلق باضطر اب الشخصية الحدية، كما أكد ألبرت أليس على أهمية زيادة تحمل

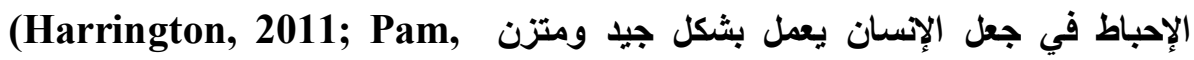

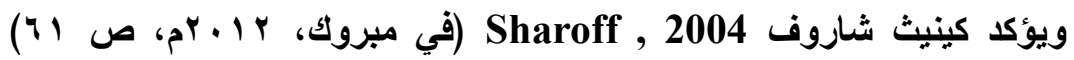

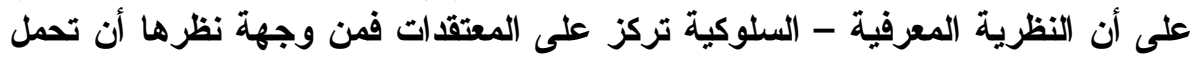

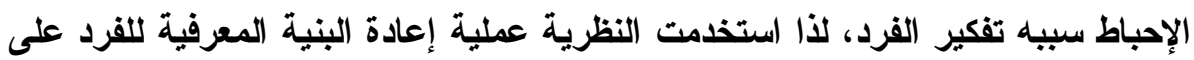

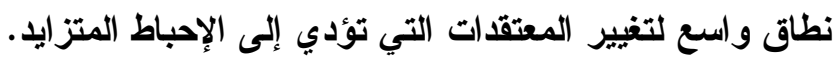
- مصادر عدم تحمل لإحباط: وصف هيرنجتون (Harrington, 2011) أربعة مصادر

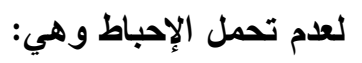
- عدم تحمل الإحباط الانفعالي Emotional intolerance ويعكس الاعتئ الاففعالات والأفكار المرتبطة بالاضطر الافي الإب الافعالي الثديد (الذي لا يمكن أن 


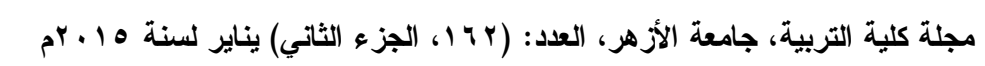

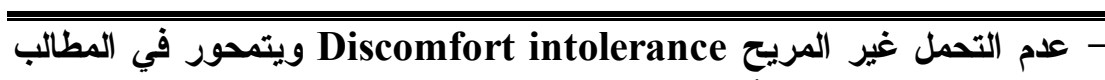
المتعلقة بان الحياة يجب أن تكون سهلة ومريحة وخالية من المشاكل. - الجدارة / الاستحقاق Entitlement يشير إلى الإحباط المتعلق بالآخرين و الأي يجب ألا نتغمس أو يحبط رغباتئا.

- عدم تحمل الإحباط الأكاديمي Achievement يتعلق بتحقيق المعتقدات الكمالية (التفوق العلمي).

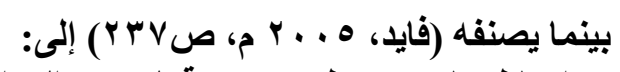

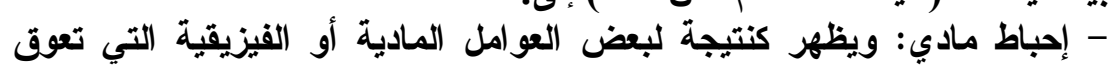
الفرد في بعض الأعمال. - مادي

- إحباط اجتماعي: وهو المتعلق بالمجتمع وثقافته كذلك ما تسببه العلاقات مع الآخرين من توتر وضيق.

- العوامل المؤثرة في تحمل لإحباط:

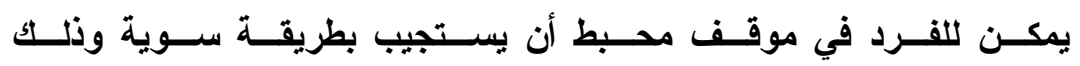

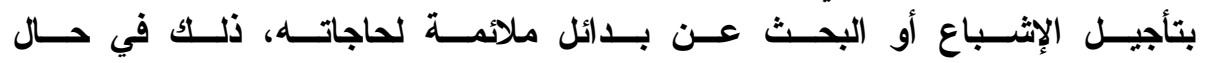

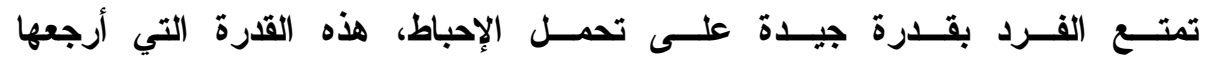
روزنزفايغ Rosenzweig إلى نمطين من العوامل المحددة ولهي هي:

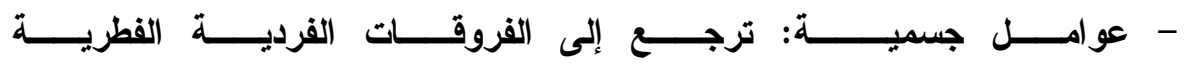

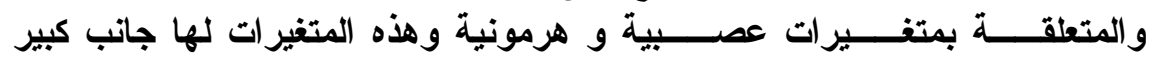

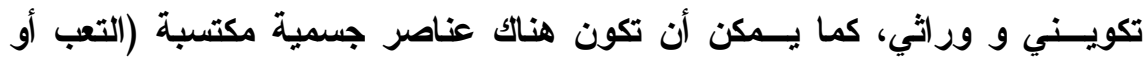
الأمر اض الجسمية).

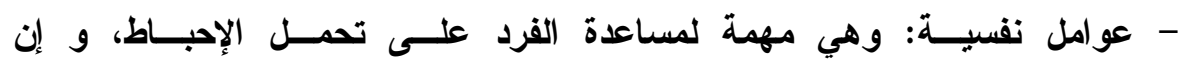

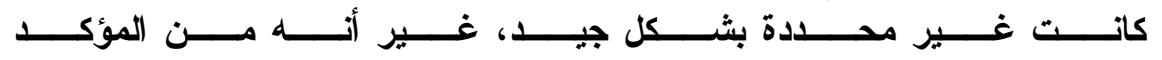

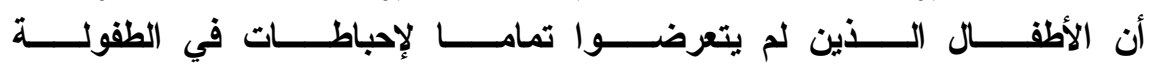

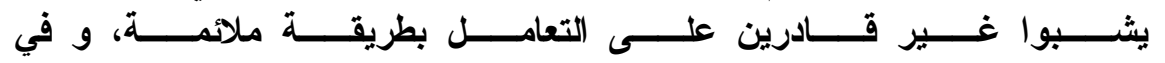

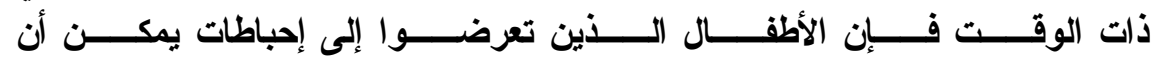

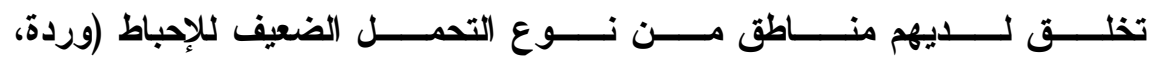
.) (

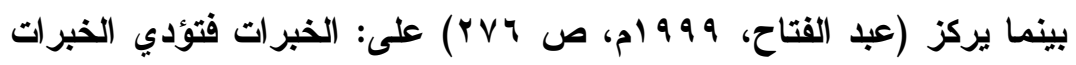

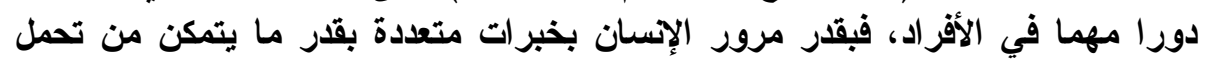
الإحباط وتقبله، ومن هنا يختلف الأفراد فيما بينهم في مدى لإنى تحلهم للإحباط. 


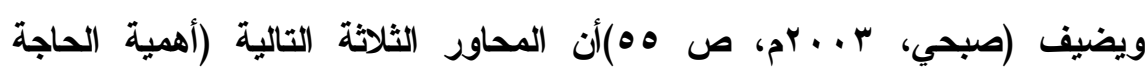

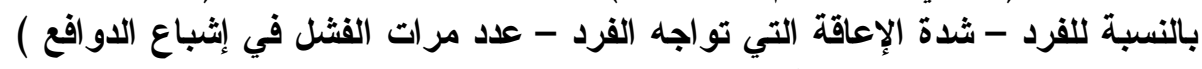
لها دورا مهما في تحديد درجة الإحباط التي يعاني منها الفردة الفرد - ذوو تحمل الإحباط المنخفض والمرتفع:

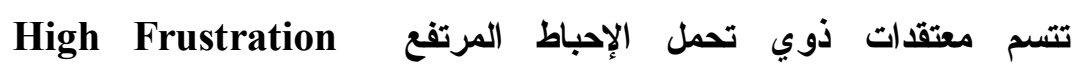

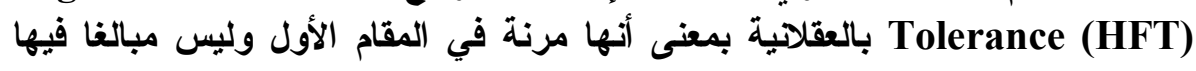

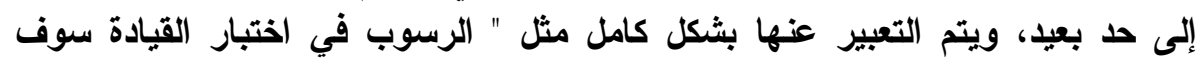

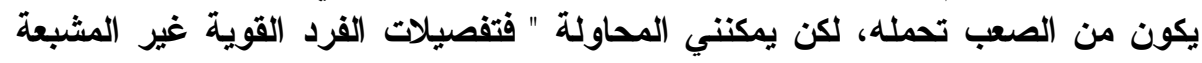

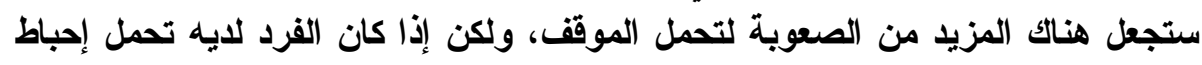

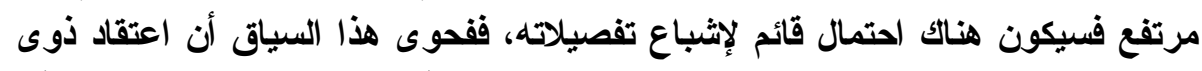

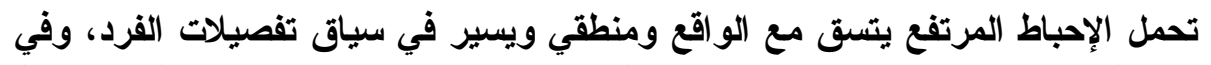

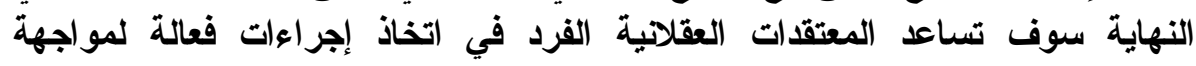

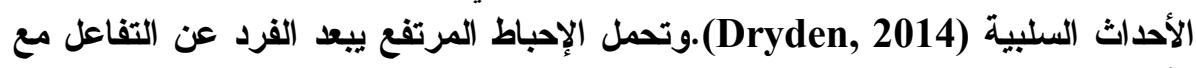

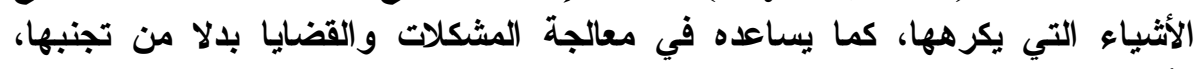

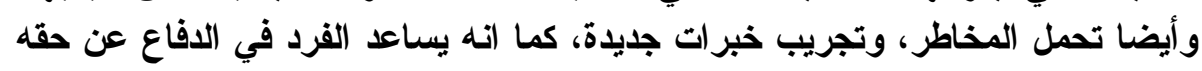

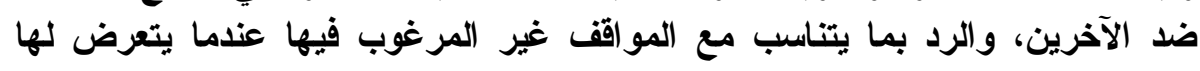

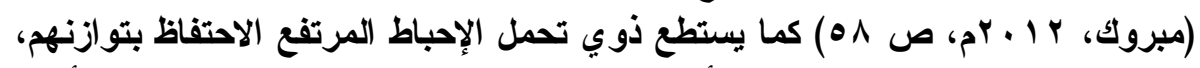

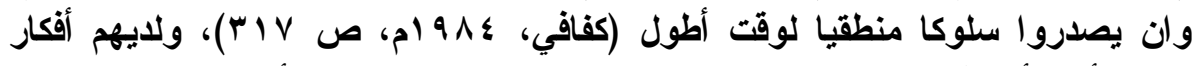

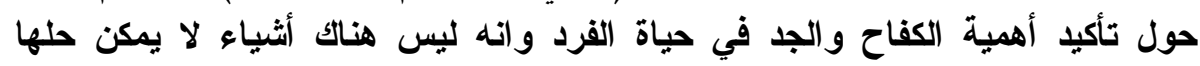

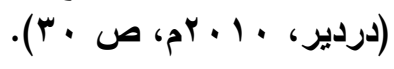

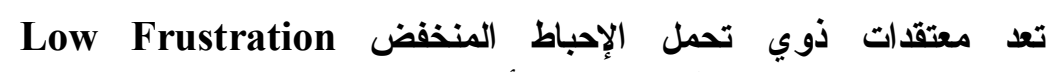
Tolerance (LFT)

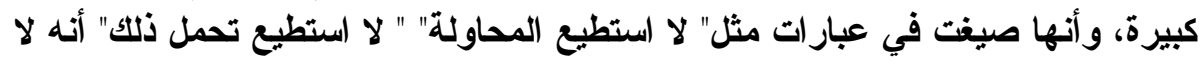

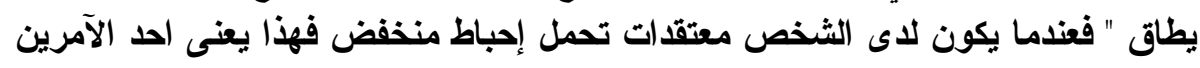
التاليين: - - أنه لن يكون متماسك. - - لن يشه أي إحساس بالسعادة مرة أخرى. فاعتقادات ذوي تحمل الإحباط المنففض غير منطقية مثل " سيكون سيئا جلا

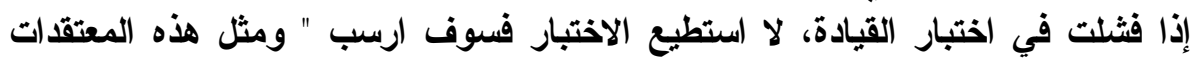

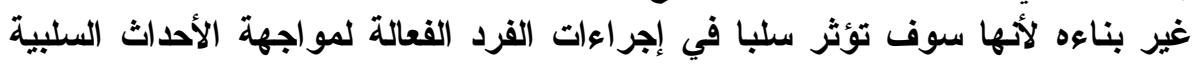




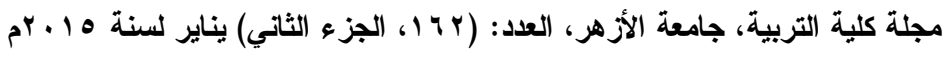

(Dryden, 2014)

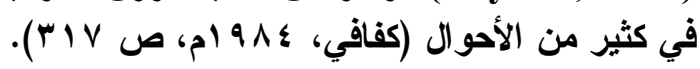

ب- الدراسات السابقة:

الاراسات التي تناولت السمات الشخصية للجانحين:

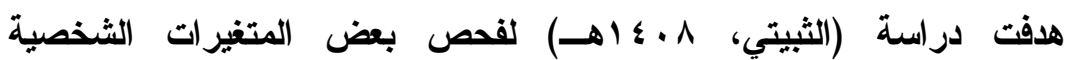

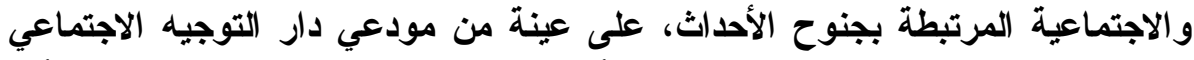

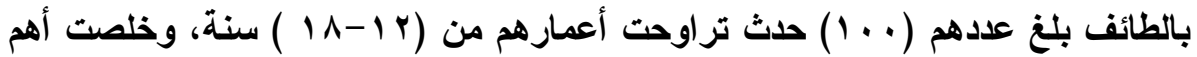

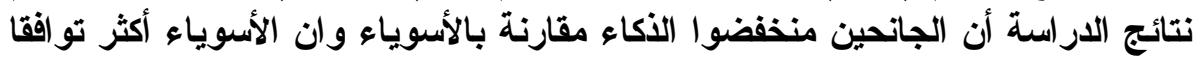
نفسيا واجتماعيا من الجانحين كما أن الجانحين يتسمون بالعدوانية.

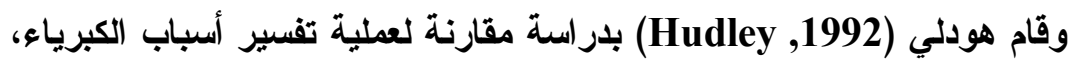

و التفاخر، والغضب، والثعور بالأنب لدى الجانحين، وغير الجانحين. وتكونت عينة

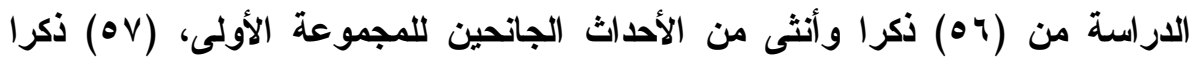

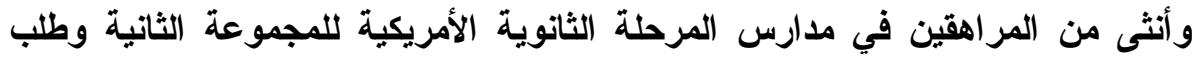

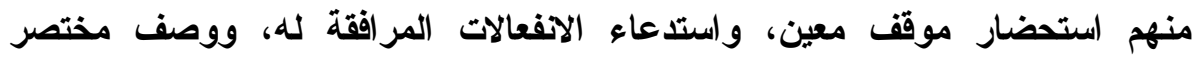

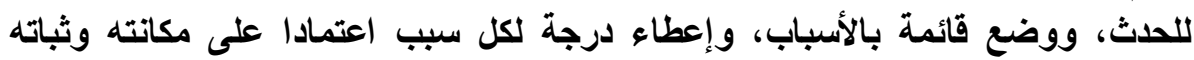

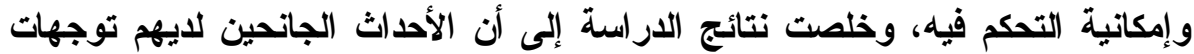

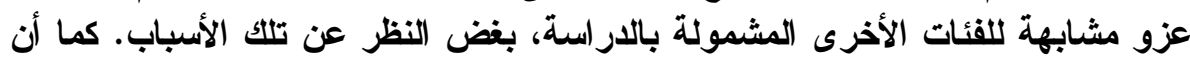
الغضب كان المصدر الأكبر لتنوع أسباب العزو، مع وجود فروق لالاسلة عائدة للعمر.

وقارن ليهنرت (Lehnert, Overtholser \& Spirito, 1994) بين أثنكال

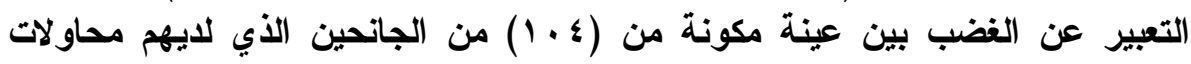

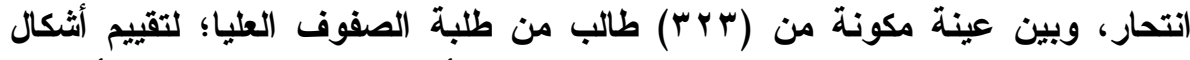

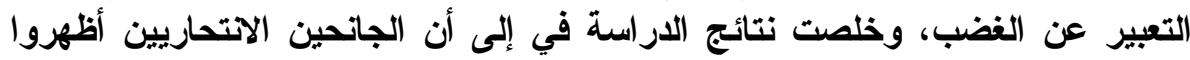

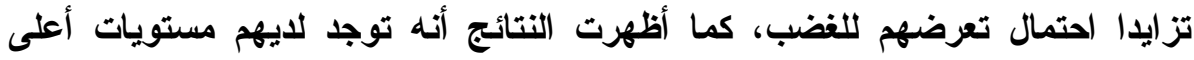

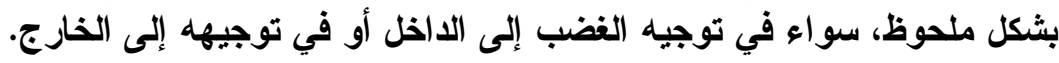

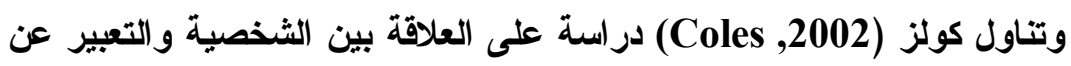

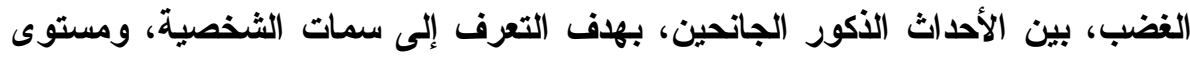

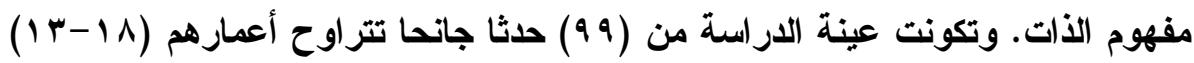

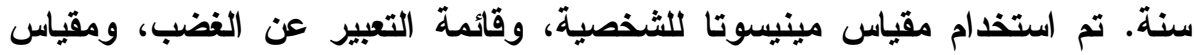

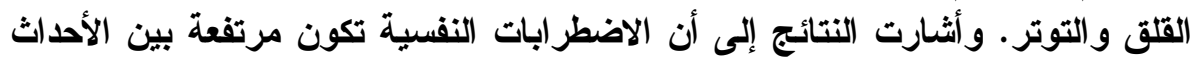

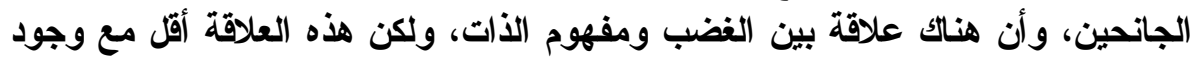
الضبط الأسري. 
- الار اسات التي تناولت تحمل الإحباط.

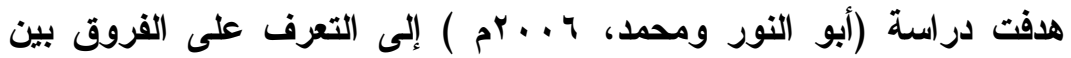

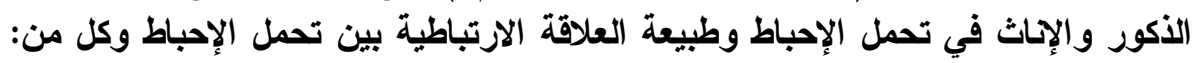

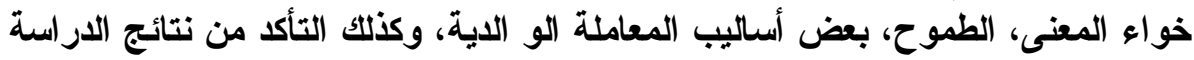

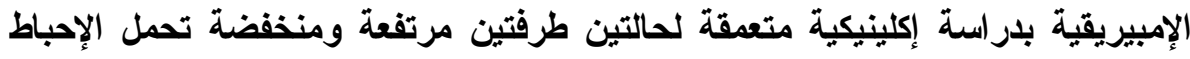

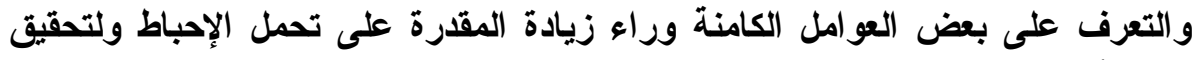

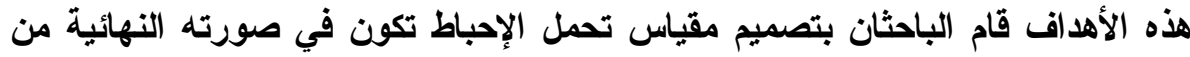

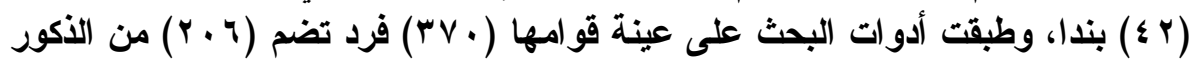

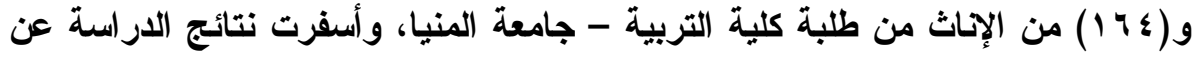

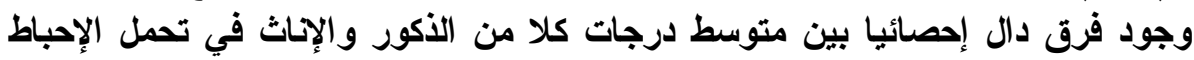
لصالح الأكور، ووجود علاقة ارتباطيه دالة موجبة بين تحمل الإحباط وكل من دن:

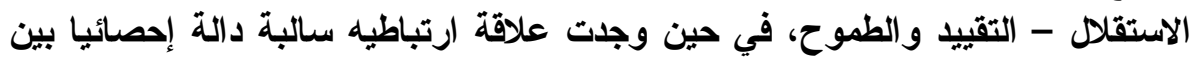

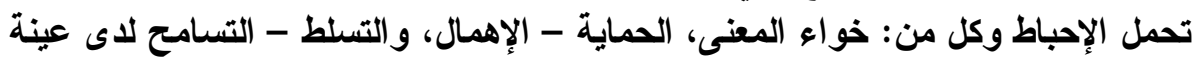

تناولت دراسة هيرنجتون (Harrington, 2005) معتقدات عدم تحمل الإحباط

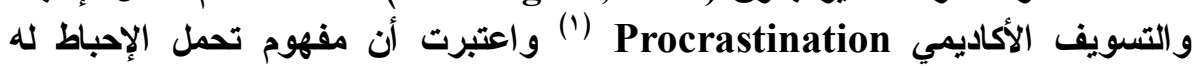

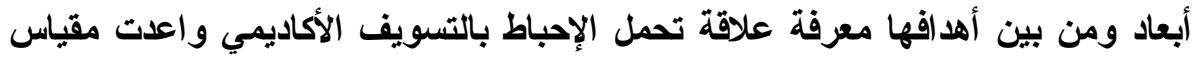

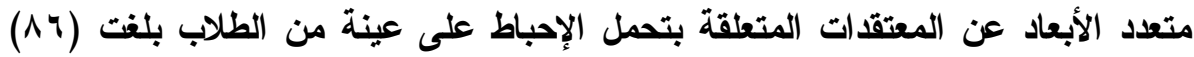

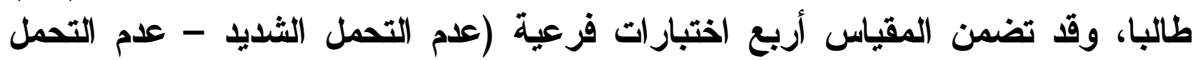

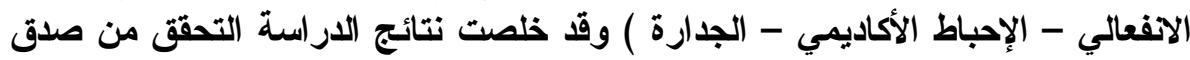
المقياس وإلى ارتباط عدم التحمل الإفعالي والإحباط الأكاديمي بثدة التسويف الأكاديمي.

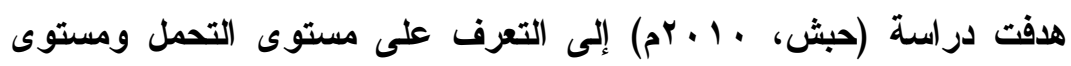

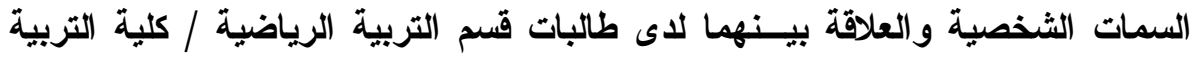

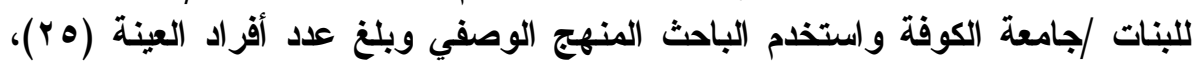

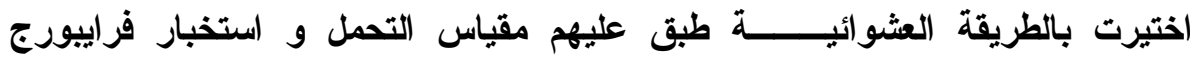

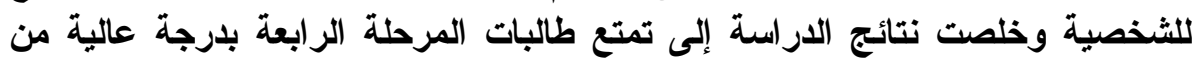

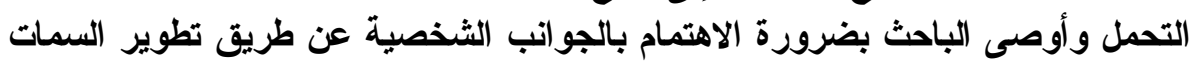

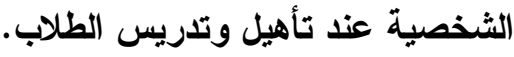

(1) يقصد بالتسويف الأكاديمي تأجيل الطالب البدء في عمل المهام الدراسية المطلوبة، وتأخيره في إتمامها

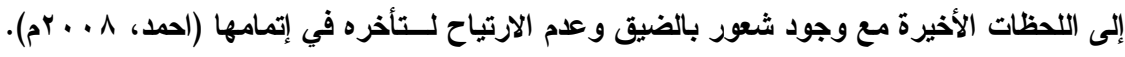




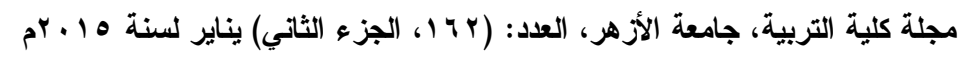

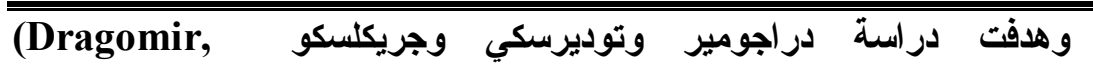
Todorescu \& Greculescu, 2011)

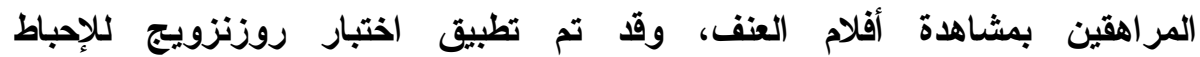
Rosenzweig frustration test

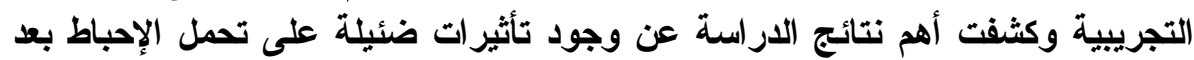

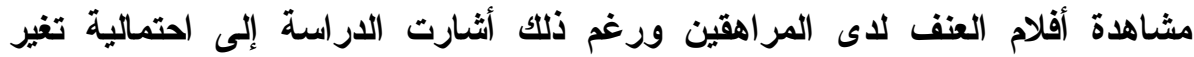
الظروف مستقبلا ويكون لوسائل الإعلام تأثير على الإحباط ويمكن أن توفر لنا لتأ وسيلة

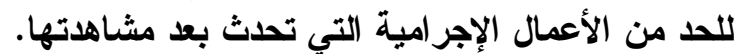

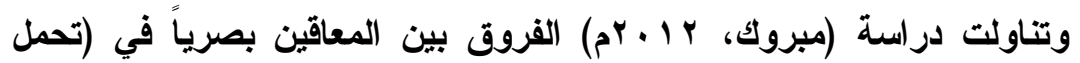

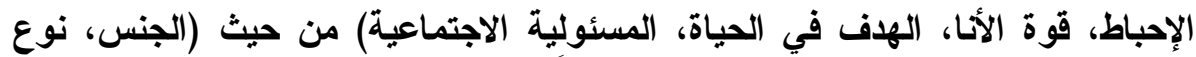

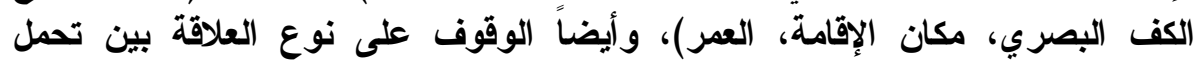

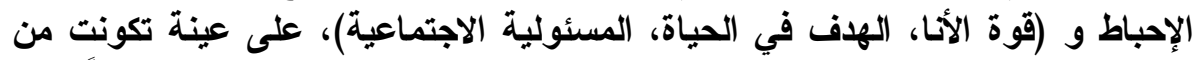

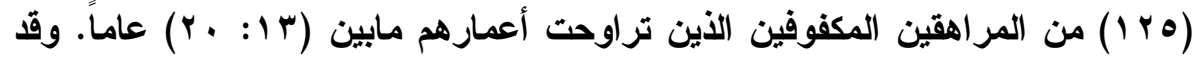

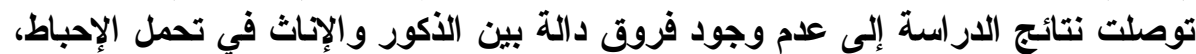

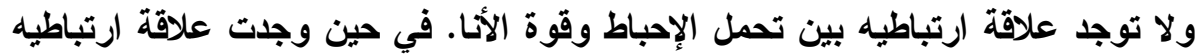

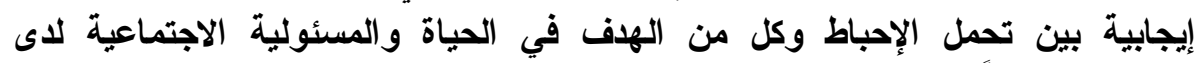

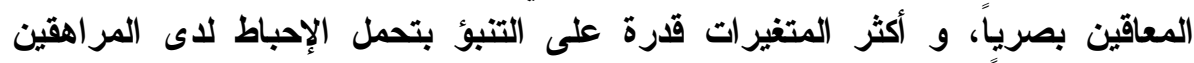
المعاقين بصرياً هو متغير الهرف في الحياة.

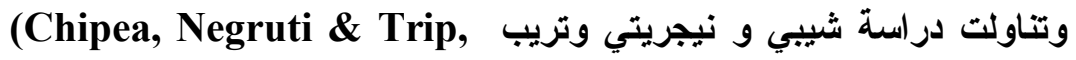

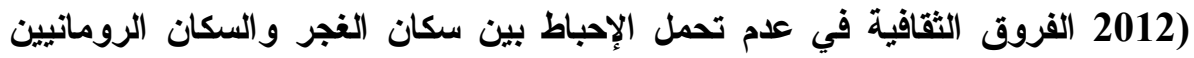

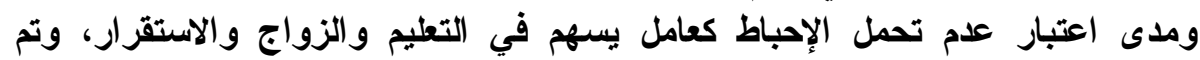

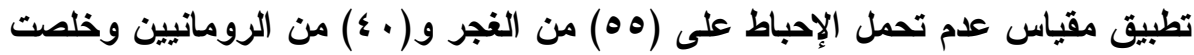

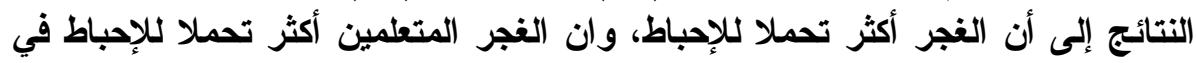
المدرسة والعمل والمستقبل، وان الغجر متعددي الصداقات مرتفعي تحمل الإحباط. وهدفت دراسة تريب ويورا (Tripe \& Bora, 2012) إلى تصميم مقياس

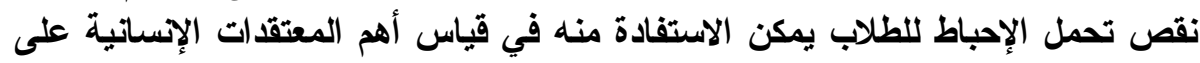

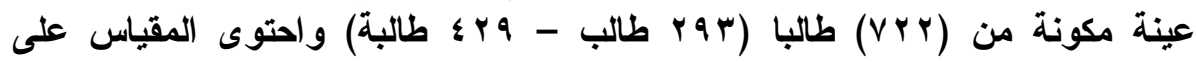

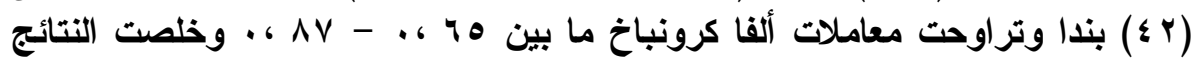
إلى أن الخصائص السيكومترية جيذة و أصبح مقياس صالح يمكن استخدامه في التقييم

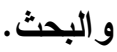

وقارنت دراسة بيوامنيش وفيروزه (Pouyamnesh \& Firoozeh, 2013) نتائج تعلم طلاب الرياضيات وعلاقتها بمستوى تحمل الإحباط، وتم تطبيق اختبار تحمل 
الإحباط على مجموعتين من طلاب المدارس الثانوية الحكومية (مجموعة للعلوم

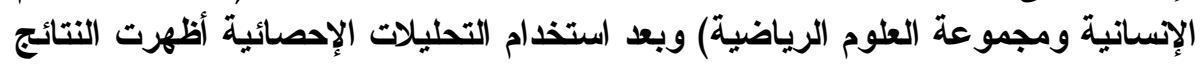

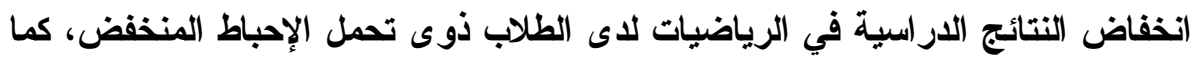

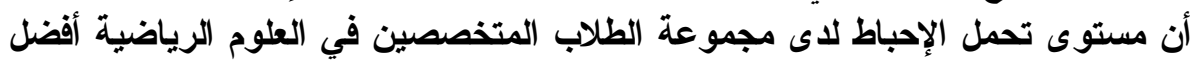
من مجموعة الطلاب المتخصصين في العلوم الإنسانية. - تعقيب على الدر اسات السابقة

- تنوعت أهداف الاراسات السابقة في تناول مفهوم تحمل الإحباط فقد أكلد دراسة

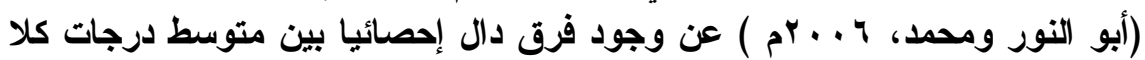

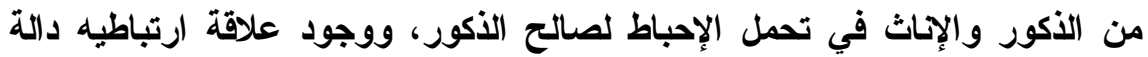

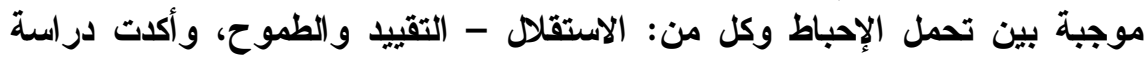
هيرنجتون أن تحمل الإحباط مفهوم متعدد الأبعاد (Harrington, 2005 ) وله وله ولكية

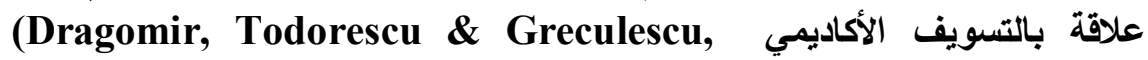

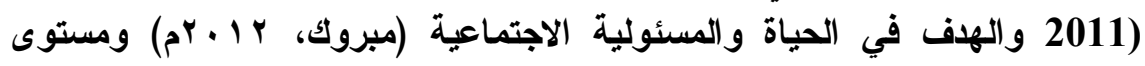

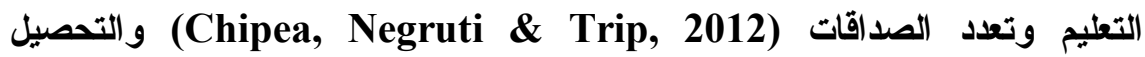
الاراسي والتخصص (Pouyamnesh \& Firoozeh, 2013)، ويمكن قياسه بمقياس تتو افر فيه الشروط السيكومترية (Tripe \& Bora, 2012). - ندرة الاراسات التي تناولت تحمل الإحباط لاى الأحداث الجاتحين - حدود علم الباحث

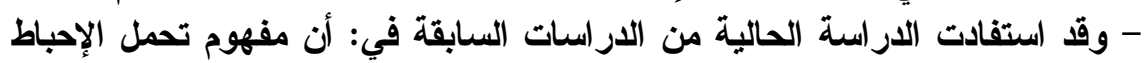

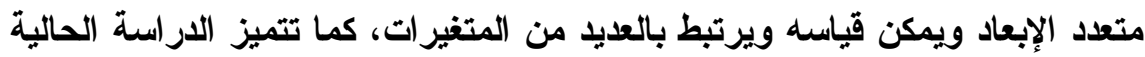

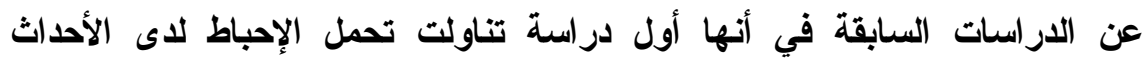

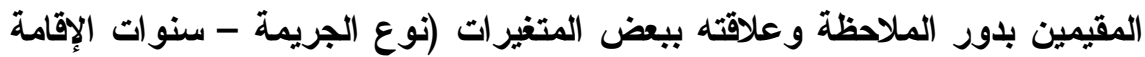
- مستوى التعليم). فروض الار اسة:

- توجد فروق ذات دلالة إحصائية في تحمل الإحباط بين الأحداث المقيمين في دور الملاحظة والعاديين في اتجاه العاديين.

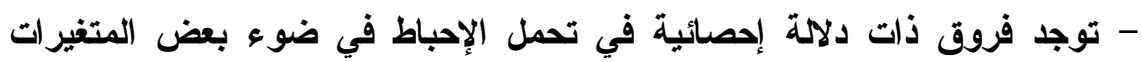

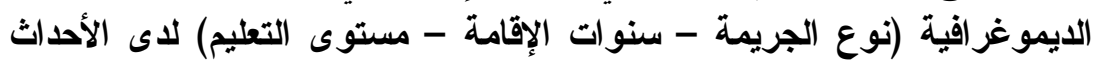

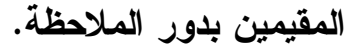


- منهج الدراسة: اعتمد الباحث في الاراسة الحالية على المنهج الوصفي حيث هدفت

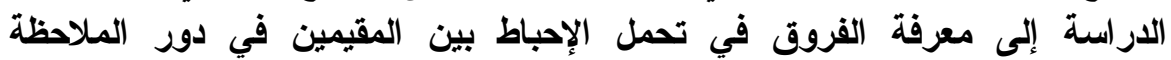

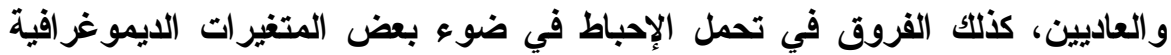
(نوع الجريمة - سنوات الإقامة - مستوى التعليم) لاى المقيمين في دور الملاحظة. - مجتمع الاراسة: تكون مجتمع الدراسة من جميع الأحداث المقيمين بدور الملاحظة

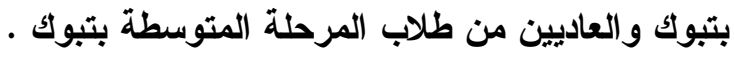

-عينة الاراسة: وعددهم ( • ع) من الأحداث المقيمين بدور الملاحظة بتبوك بمتوسط

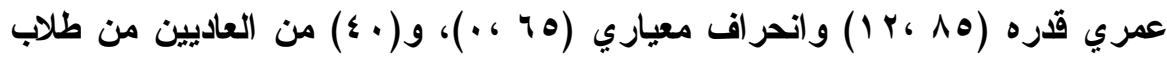

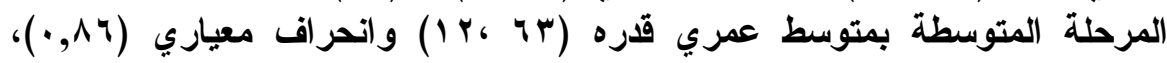

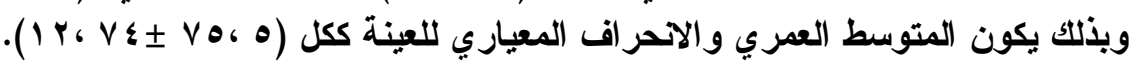

$$
\text { - أدوات الدر اسة و إجر اءاتها: }
$$

- مقياس تحمل الإحباط: (Harrington, 2005) ترجمة وإعادة تقتين الباحث قام بوضعه نيل هيرنجتون Neil Harrington, 2005 ويتكون من ^^ب بندا،

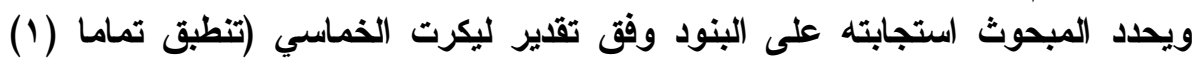

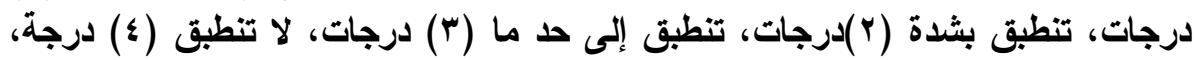

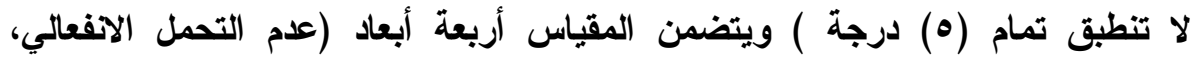

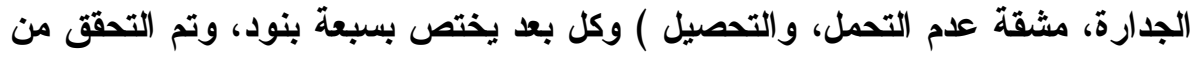

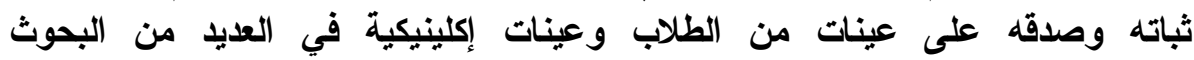

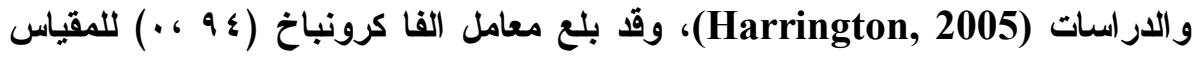

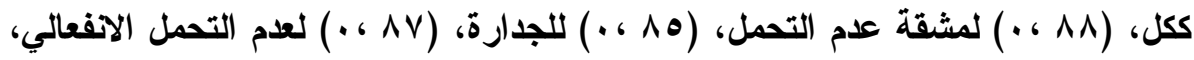

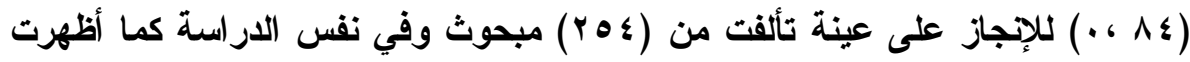

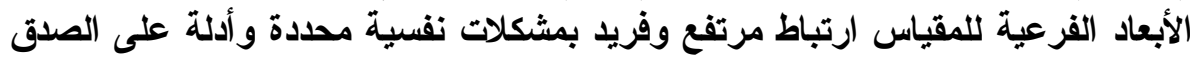

(Ozer, Demir, Harrington, 2012)

- التحقق من الخصائص السيكومتريه للمقياس: بالإضافة إلى استخدامها في العديد من

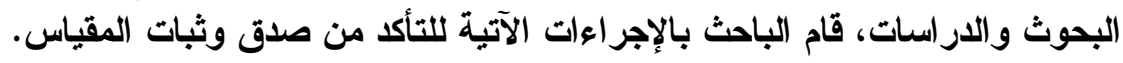

أ- مدى صلاحية عبارات المقياس: 
- قام الباحث بترجمة المقياس ثم عرضه على أربعة محكمين ينتمون إلى القياس

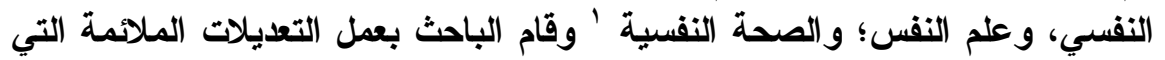

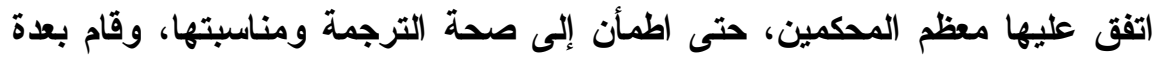

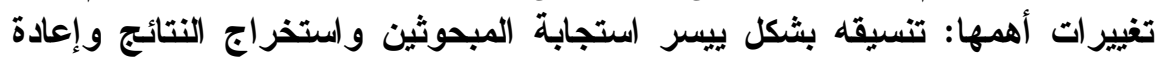

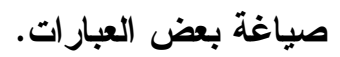

- صدق الاتساق الداخلي: تم تطبيق المقياس على عينة قوامها ـ ب مبحوث من مدينة

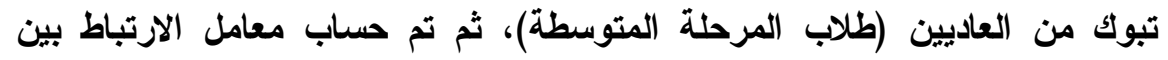

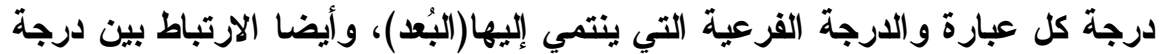

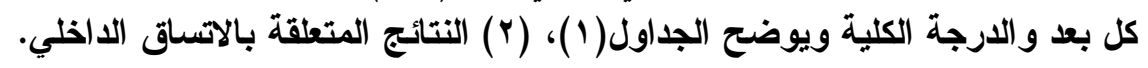

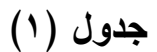

يوضح قيم معاملات الارتباط بين درجة كل بند والدرجة الكلية للبُعد الذي ينتمي إليه

\begin{tabular}{|c|c|c|}
\hline (بي معامل ارتباط & البعــــــ & رقم البند \\
\hline$\cdot, 09$ & \multirow{7}{*}{ مشقة عدم التحمل. } & -1 \\
\hline., 79 & & $-r$ \\
\hline$\cdot, \vee \wedge$ & & $-r$ \\
\hline$\cdot, 7 V$ & & $-\varepsilon$ \\
\hline$\cdot, \vee q$ & & -0 \\
\hline$\cdot, \vee \wedge$ & & -9 \\
\hline$\cdot, V \varepsilon$ & & $-V$ \\
\hline$\cdot, \bullet \wedge$ & \multirow[b]{3}{*}{ عدم التحمل الاتفعالي. } & $-\Lambda$ \\
\hline$\cdot, 79$ & & -9 \\
\hline$\cdot, 91$ & & -1 \\
\hline
\end{tabular}

(1) د.شاهر خالد سليمان أستاذ القياس النفسي المشارك جامعة تبوك، د. عبد الـرحمن عثـــان أســتاذ

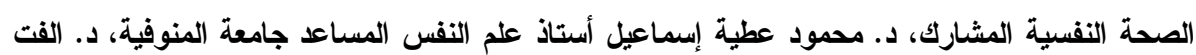
حسين كلة أستاذ علم النفس المساعد جامعة تبوك. 
مجلة كلية التربية، جامعة الأزهر، العدد: (r ا 1، الجزء الثاني) يناير لسنة ه 1 ـ بم

\begin{tabular}{|c|c|c|}
\hline 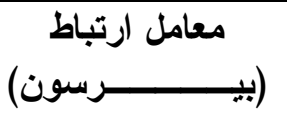 & البعــــــ & رقم البند \\
\hline$\cdot, \vee V$ & & -11 \\
\hline$\cdot, V r$ & & Ir \\
\hline$\cdot, 79$ & & 14 \\
\hline$\cdot, V V$ & & $1 \varepsilon$ \\
\hline$\cdot, \Lambda$. & \multirow{7}{*}{ الجدارة. } & -10 \\
\hline - & & -17 \\
\hline$\cdot, \wedge \varepsilon$ & & $-1 V$ \\
\hline$\cdot, 79$ & & -11 \\
\hline., $7 V$ & & -19 \\
\hline$\cdot, \mathrm{VV}$ & & $-r$. \\
\hline.,$\vee 0$ & & $-Y_{1}$ \\
\hline$\cdot, V \varepsilon$ & \multirow{7}{*}{ الاتجاز } & $-Y Y$ \\
\hline$\cdot, 9 \vee$ & & $-Y r$ \\
\hline$\cdot, \vee 99$ & & $r \varepsilon$ \\
\hline$\cdot, \vee \vee 7$ & & ro \\
\hline$\cdot, \vee \circ$ & & $r q$ \\
\hline$\cdot, V V$ & & $r V$ \\
\hline., $1 \vee q$ & & $r \wedge$ \\
\hline
\end{tabular}

$-109-$ 
جدول (r)

يوضح قيم معاملات الارتباط بين درجة كل بُعد والدرجة الكلية لمقياس تحمل الإحباط

\begin{tabular}{|c|c|c|}
\hline معامل الارتباط & 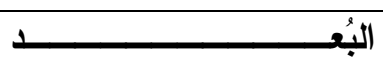 & b \\
\hline$\cdot, V r$ & - مشقة عدم التحمل. & -1 \\
\hline$\cdot, \nabla r$ & - عدم التحمل الآفعالي. & $-r$ \\
\hline$\cdot, \wedge \varepsilon$ & - الجدارة. & $-r$ \\
\hline$\cdot, \vee \vee q$ & - الاتجاز . & $-\varepsilon$ \\
\hline
\end{tabular}

ويتضح من جدول (Y) السابق أن جميع قيم معاملات الارتباط دالة عند مستوى ه، .

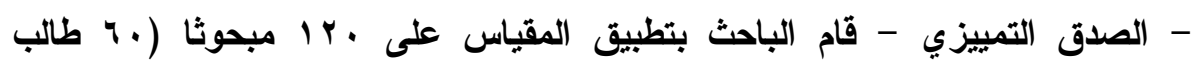

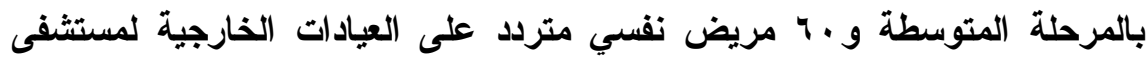

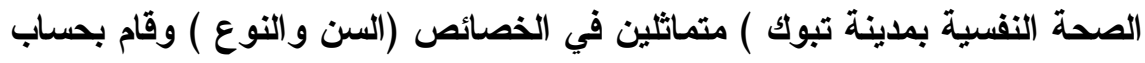

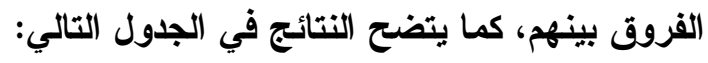

جدول (r)

\begin{tabular}{|c|c|c|c|c|c|c|}
\hline مستوى الدلامة & القرق في & الحرية & 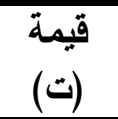 & $\varepsilon$ & p & عدد العينة \\
\hline \multirow[b]{2}{*}{$\cdot, \cdots$} & \multirow[b]{2}{*}{ or, \&. } & \multirow[b]{2}{*}{111} & \multirow[b]{2}{*}{$r \cdot, 1 r$} & $\wedge \wedge, \mu \wedge$ & $97,9$. & ( • † ) عادي \\
\hline & & & & $v, I V$ & $\varepsilon r, 0$. & مريض (· ن) \\
\hline
\end{tabular}

يتضح من نتائج جدول (r) السابق وجود فروق دالة إحصائيا بين متوسطات

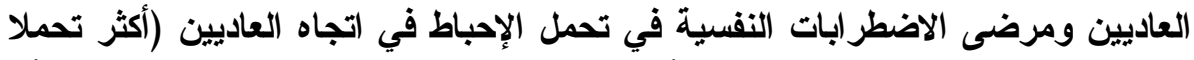

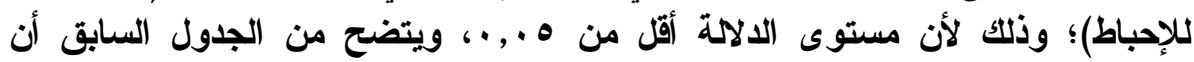

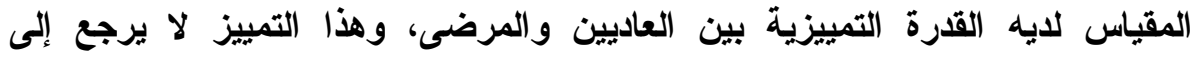
الصدفة ولكن إلى قدرة المقياس على التمييز

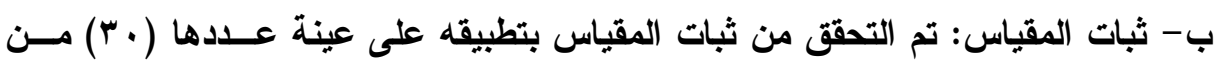

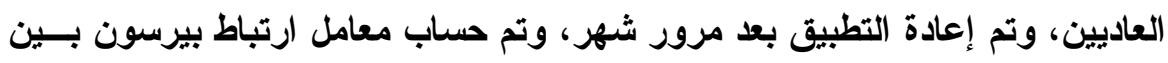




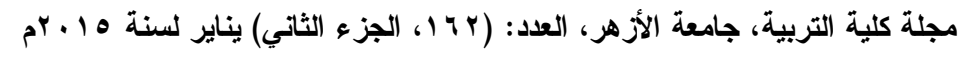

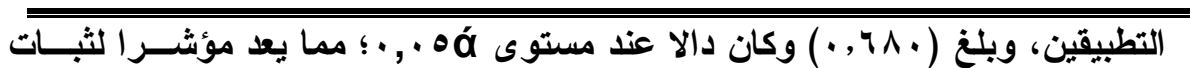

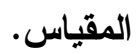

- إجراءات تطبيق الدراسة: سارت إجراءات البحث وفقاً للخطوات الآتية:

قام الباحث بالاطلاع على التراث النظري لمتغيرات البحث، والاطلاع على البحوث الباث

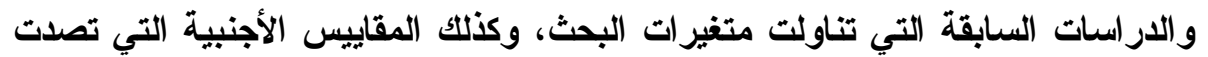

لمفهوم تحمل الإحباط.

ا- قام الباحث بترجمة وإعادة تقنين مقياس علدم التحمل بعد التحةـق مــن خصائـصه السيكومتريه (الصدق والثبات).

r- قام الباحث بتطبيق المقياس على عينة من العاديين ونزلاء دور الملاحظة.

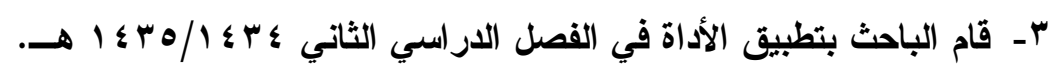
ـ ـ قام الباحث بتحليل البيانات ومعالجتها إحصائيا وجدولتها للتحقق من فروض الدراسة.

$$
\begin{aligned}
& \text { الأسباليب الإحصائية: } \\
& \text { • معامل ارتباط بيرسون. }
\end{aligned}
$$

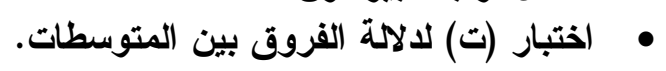

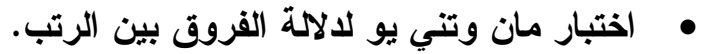

نتائج الدر اسدة:

الفرض الأول:توجد فروق ذات دلالة إحصائية في تحمل الإحباط الأحداث بين المقيمين في دور الملاحظة والعاديين في اتجاه العاديين، وتتضح دوله النتائج في الجدول التالي:

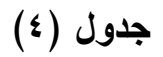

\begin{tabular}{|c|c|c|c|c|c|c|}
\hline \multicolumn{7}{|c|}{ بلور الملاحظة } \\
\hline مستوى الدلاكة & الفي الفرق & الحرية & قيمة & $\varepsilon$ & r & عدد العينة \\
\hline \multirow[b]{2}{*}{$\cdot, \cdots$} & \multirow{2}{*}{ } & \multirow{2}{*}{$\vee \wedge$} & \multirow{2}{*}{$\Lambda, \mu_{1}$} & IV,V. & $1,1,0 Y$ & ( • ـ ) عاديين \\
\hline & & & & $I V, \Lambda V$ & $\curlyvee \wedge, \& \wedge$ & بدور الملاحظة \\
\hline
\end{tabular}

يوضح الفروق في تحمل الإحباط بين متوسطي مجموعتي العاديين والأحداث المقيمين 
يتضح من جدول (؛) السابق وجود فروق دالة إحصائياً بين متوسطات

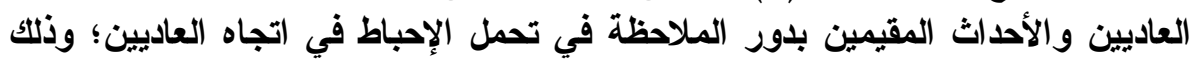

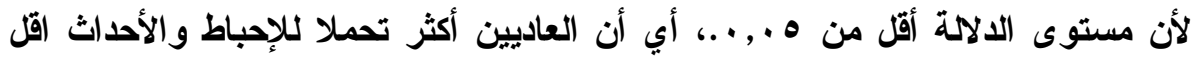

تحملا للإحباط.

ويرجع الباحث النتيجة أن العاديين أكثر تحملا للإحباط و والأحداث الجانحين

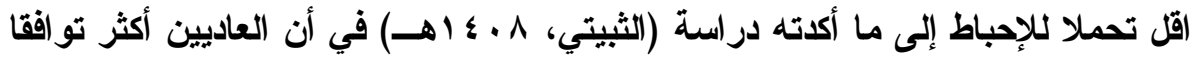

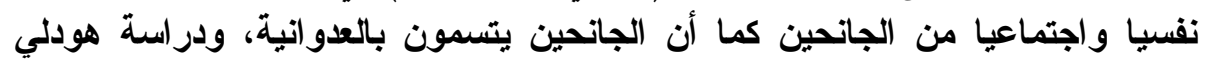

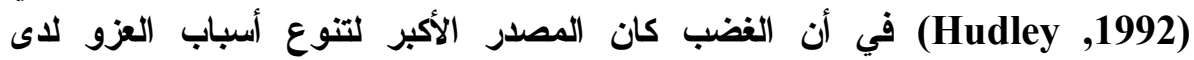

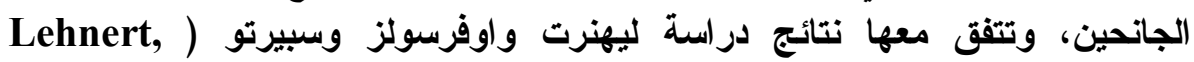

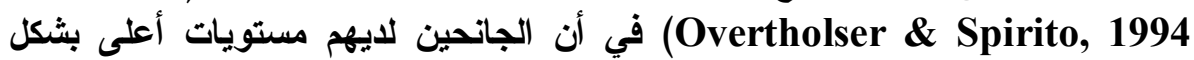

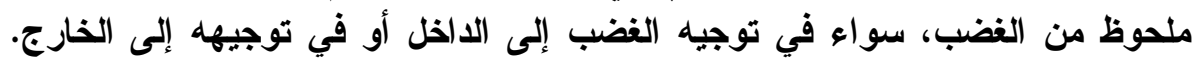
كما أكدت دراسة كولز (Coles 2002) على أن الاضطر ابات النفسية الكون الفئ مرتفعة بين

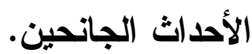

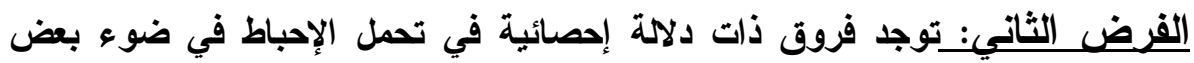

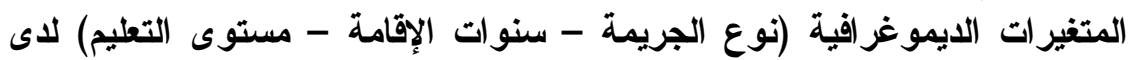
الأحداث المقيمين بدور الملاحظة. وتفرع من الفرض الفريمة الرئيس السابق الفروض

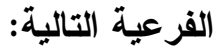
أ- توجد فروق ذات دلاية إحصائية في تحمل الإحباط بين المدانين بجرائم أخلاقية

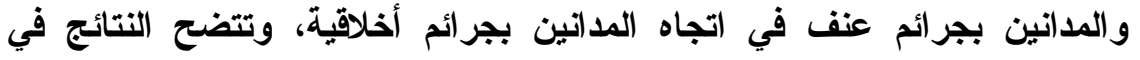

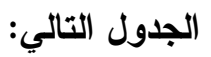

جدول (0)

يوضح الفروق في تحمل الإحباط بين الأحداث المدانين بجرائم أخلاقية و المدانين بجرائم عنف

\begin{tabular}{|c|c|c|c|c|c|}
\hline الالالة & قيمة () & مجموع & متوسط الرتب & العينة & المجموعة \\
\hline \multirow[t]{2}{*}{$\cdot, \cdots$} & \multirow[t]{2}{*}{7} & Y17 & $1 \cdot, \Lambda$. & $r \cdot$ & المدانين بجرائم عنف \\
\hline & & $7 \cdot \varepsilon$ & $r \cdot, r$. & $r \cdot$ & المداتين بجرائم \\
\hline
\end{tabular}




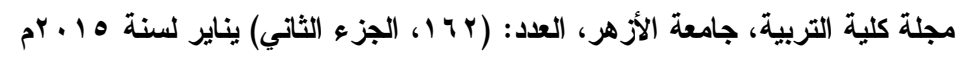

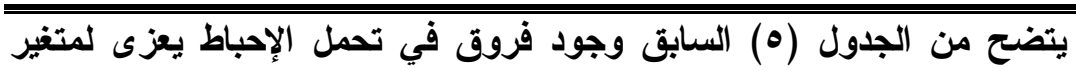

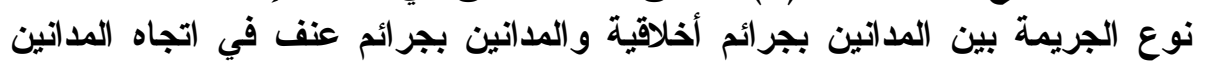
بجرائم أخلاقية.

ويتضح من النتيجة السابقة أن المدانين في جرائم عنف أقل تحملا للإحباط

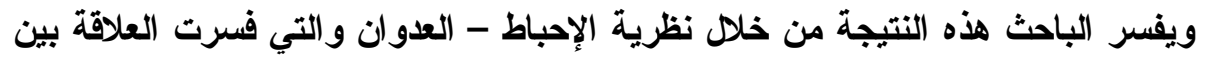

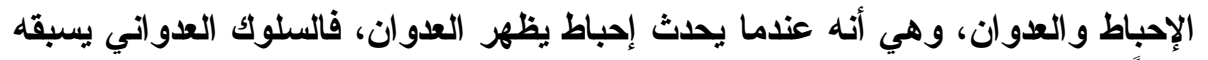

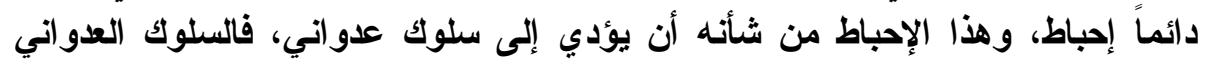

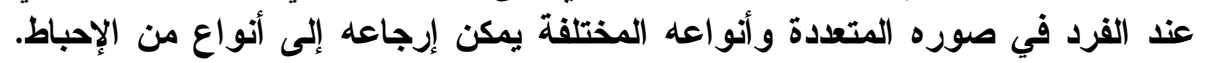

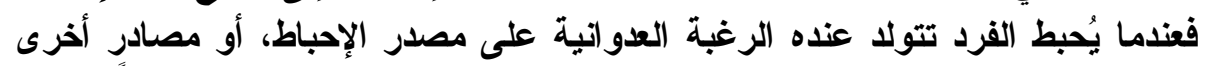

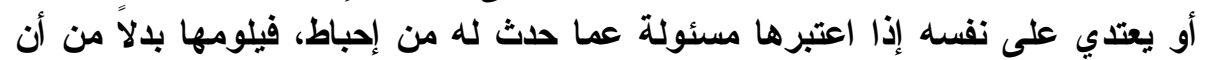

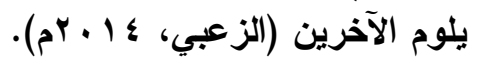

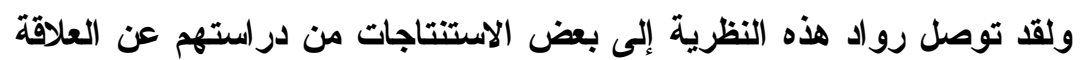

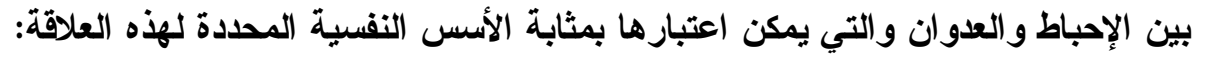
أ- تختلف شدة الرغبة في السلوك العدواني باختلاف كمية الإحباط الذي يواجها الفرد. ب- عندما يتعرض الفرد للإحباط ويستجيب عدوانياً ضد مصدر إحباطه يحدث تفريغاً

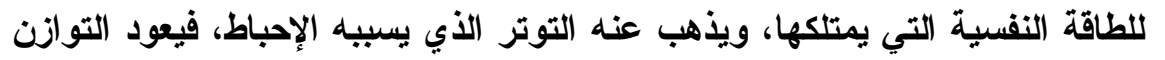
الداخلي للقرد.

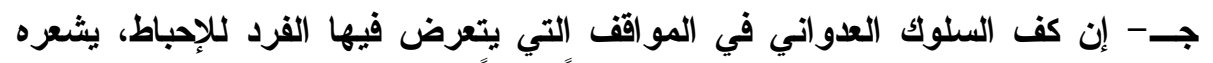

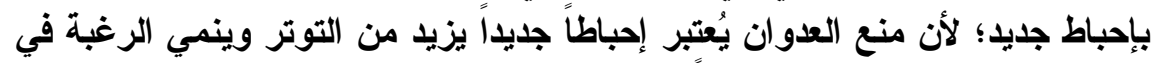

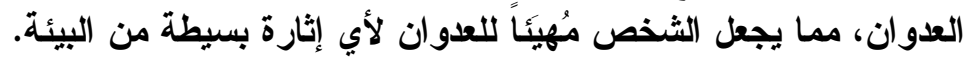

د - قد يقع الثخص في صر اع بسبب الإحباط إذا تساوت رغبته في العدوان على مصدر

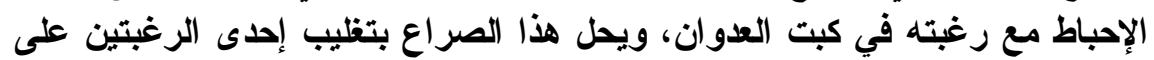

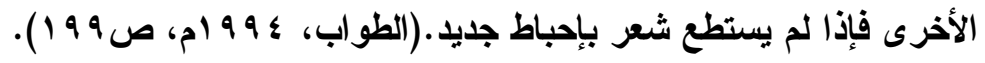

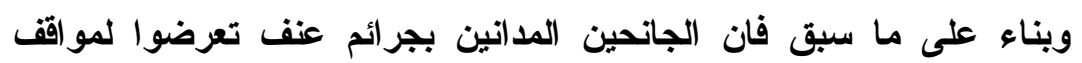

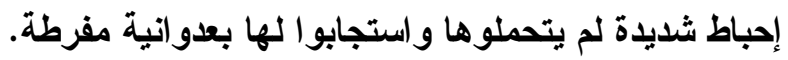

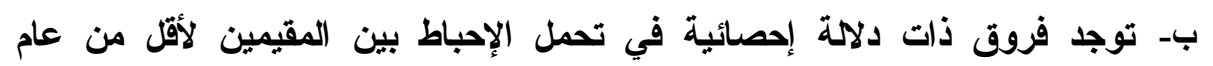

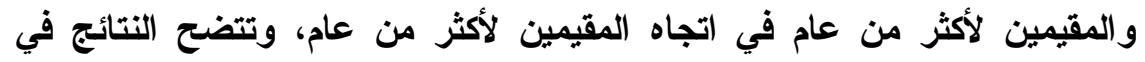
الجدول التالي: لاكير 
جدول (7)

يوضح الفروق في تحمل الإحباط بين الأحداث المقيمين لأقل من عام والمقيمين لأكثر من عام

\begin{tabular}{|c|c|c|c|c|c|}
\hline مستوى الدلالة & قيمة ( ق U & مجموع الرتب & متوسط & العينة & المجموعة \\
\hline \multirow[t]{2}{*}{$\cdot, \cdots$} & \multirow[t]{2}{*}{$0,0}$. & $Y 10,0$. & $1 \cdot, \vee \wedge$ & r. & المقيمين لأقّل من عام \\
\hline & & $7 . \leq, 0$. & $r \cdot, r r$ & $r$. & المقيمين لأكثر من \\
\hline
\end{tabular}

يتضح من جدول (†) السابق وجود فروق في تحمل الإحباط يعزى لمتغير

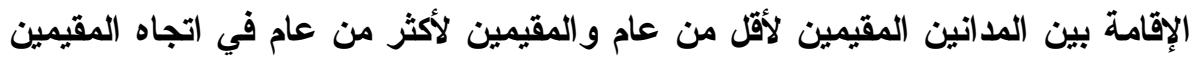
لأكثر من عام.

ويرجع الباحث هذه النتيجة إلى عامل الخبرة فالمقيمين لأكثر من عام أصبحوا

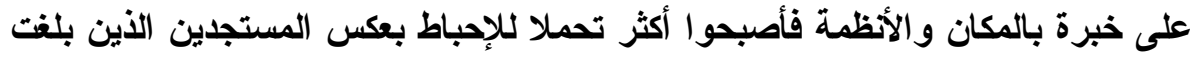

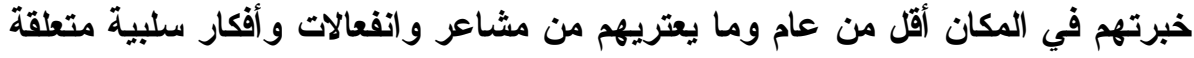

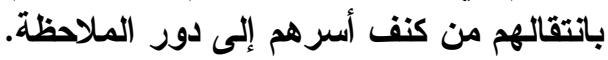

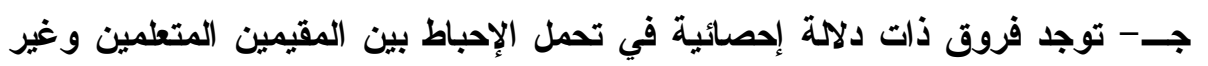

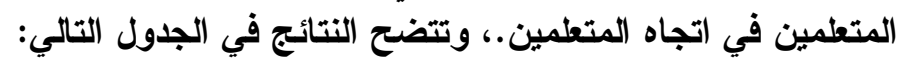

(v) جدول

يوضح الفروق في تحمل الإحباط بين الأحداث المقيمين المتعلمين وغير المتعلمين

\begin{tabular}{|c|c|c|c|c|c|}
\hline مستوى الدلالة & قيمة () & مجموع & متوسط & العينة & المجموعة \\
\hline \multirow[t]{2}{*}{,$\cdots$} & \multirow[t]{2}{*}{11} & YYI & 11,00 & $r$. & غير المتعلمين \\
\hline & & 099 & $r 9,90$ & $r$. & المتعلمين \\
\hline
\end{tabular}

يتضح من الجدول (V) السابق وجود فروق في تحمل الإحباط يعزى لمتغير

مستوى التعليم بين المقيمين المتعلمين وغير المتعلمين في اتجاه المتعلمين.

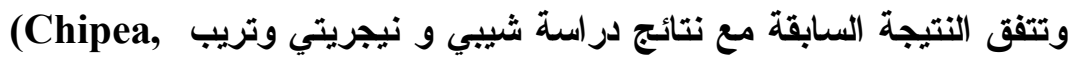

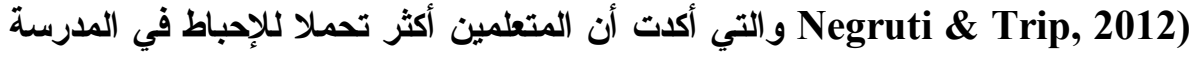

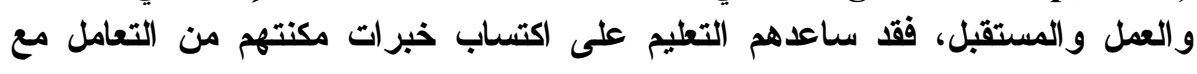




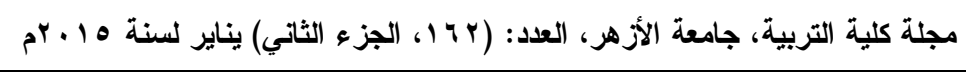

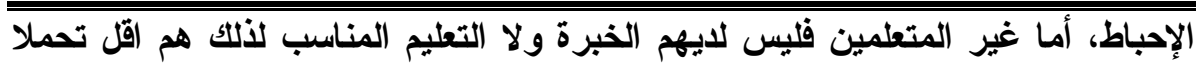

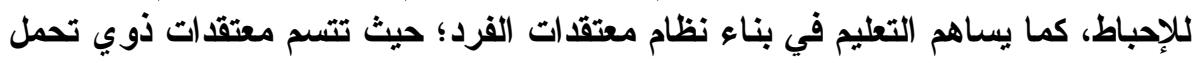
الإحباط المرتفع (HFT) مرنة في المقام الأول وليس مبالغا فيها إلى حد بعيد، وفحوى هذا السياق أن العتى العقاد ذوى تحمل الإحباط المرتفع يتسق مع الو اقو فئ ومنطقي (Dryden, 2014).

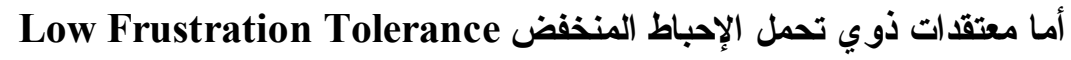

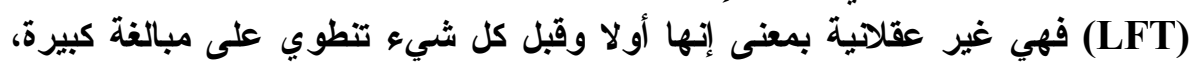

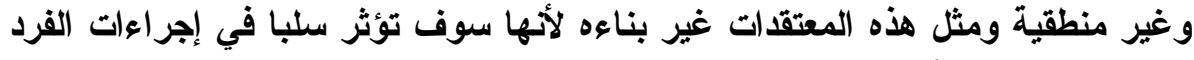

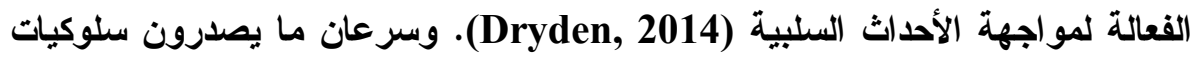

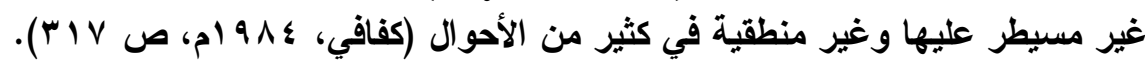

$$
\text { خاتمة وتوصيات الار اسة: }
$$

تتضح من نتائج الدراسة السابقة أن المقيمين في دور الملاحظة اقل تحملا

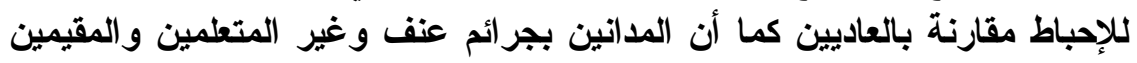

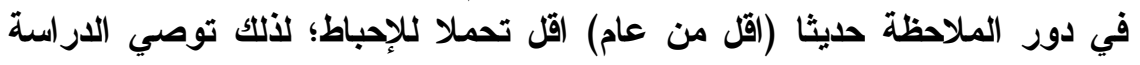
- - لمرورة توجيه الأنظار إلى شريحة مهمة من المجتمع وهي المقيمين بدور الملاحظة وهذه الفئة تحتاج إلى رعاية تنمية الجوانب الإيجابية لايهم.

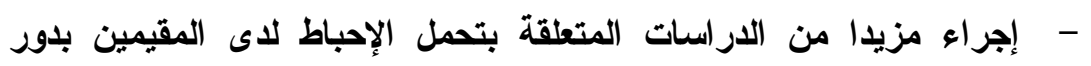

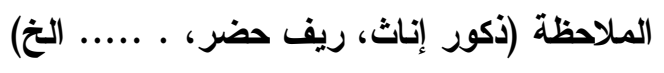

- - تصميم وتطبيق برامج إرشادية موجهه لزيادة تحمل الإحباط للمقيمين بدور الملاحظة وانعكاس ذلك على تو اقفهم وصحتهم النفسية. 


$$
\text { المر اجع و المصادر }
$$

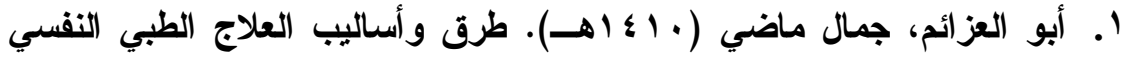

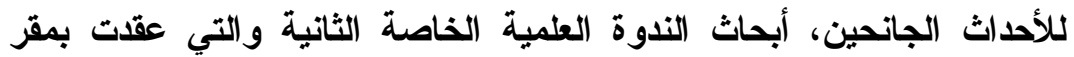

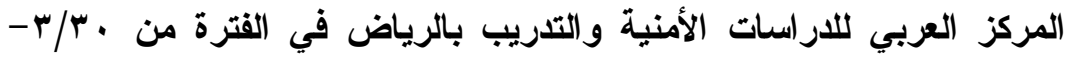

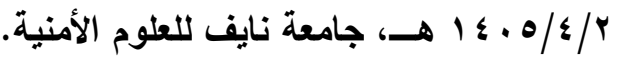

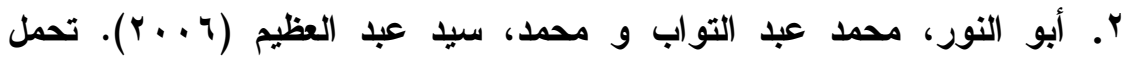

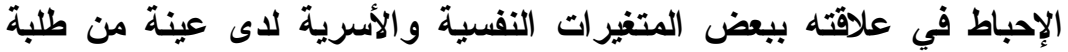

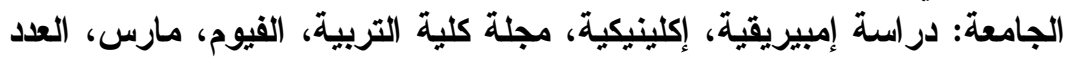

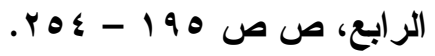

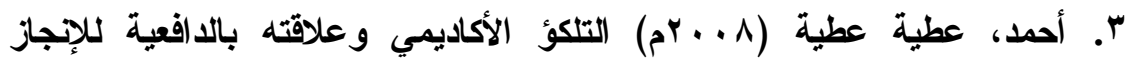

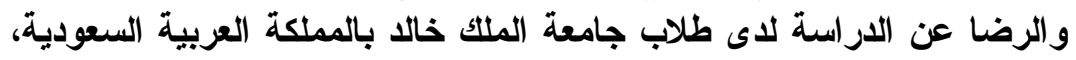

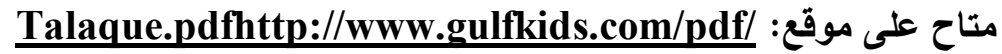
؛. أولبسير، جويدة، و99 19، المهارات الاجتماعية وأثرها في ظهور السلوك

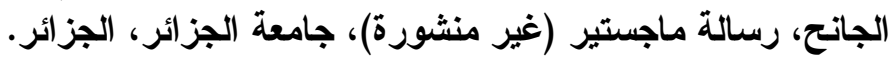

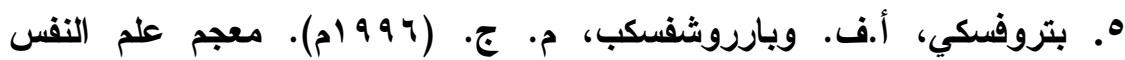

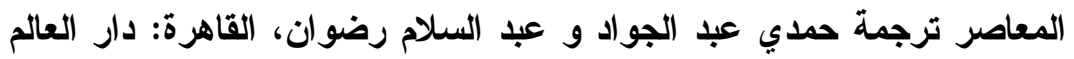
الجديد.

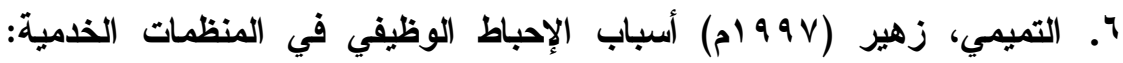

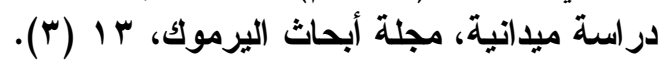

V. الثبيتي، علي خضر (1 • ـ أهـ)در اسة بعض المتغيرات الثخصية والاجتماعية

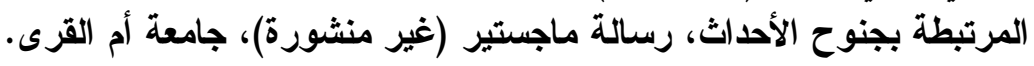

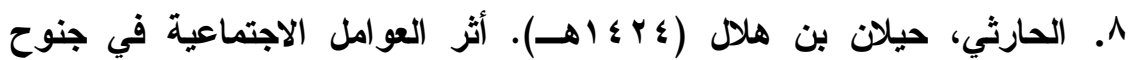

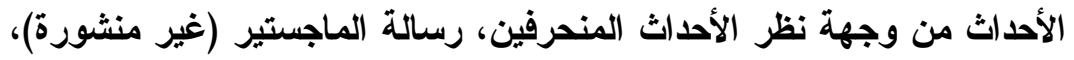

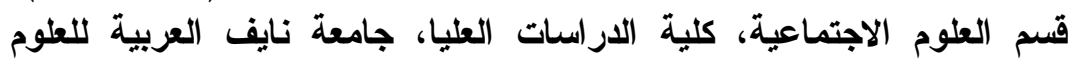

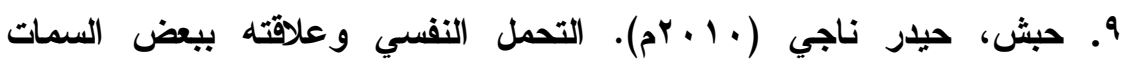
الثخصية لطالبات قسم التربية الرياضية /جامعة الكوفة، مجلة علوم التوم التربية

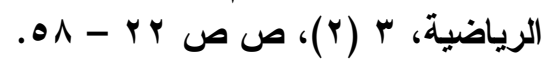




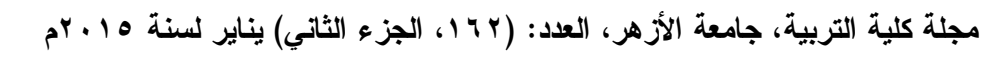

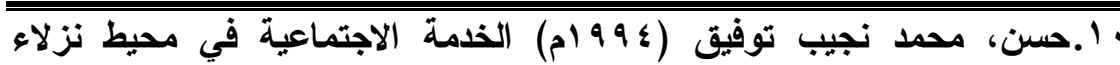

السجون والأحداث، القاهرة: مكتبة الأجلو المصرية.

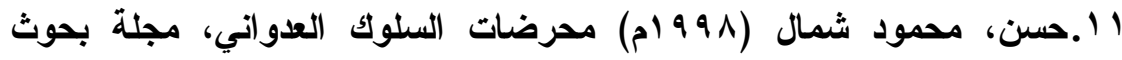

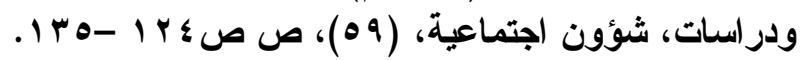

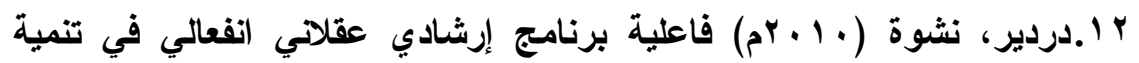

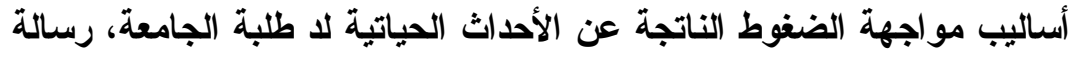

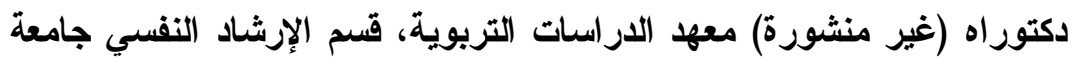

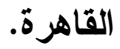

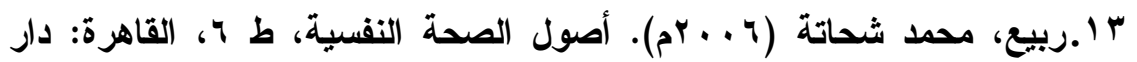

غريب للطباعة والنشر.

؛ ا. الزعبي، ابتسام عبد الله ( أ ـ rم). النظريات المفسرة للسلوك العدواني، متاح موقع:

على

http://www.gulfkids.com/ar/index.php?action=show art\&

\section{$\underline{\text { ArtCat }=3 \& i d=1396}$}

1 السمالوطي، نبيل محمد (برو ام) الدراسة العلمية للسلوك الإجرامي، جدة:

$$
\text { دار الثروق. }
$$

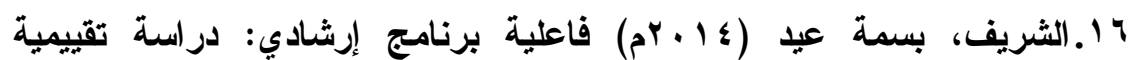

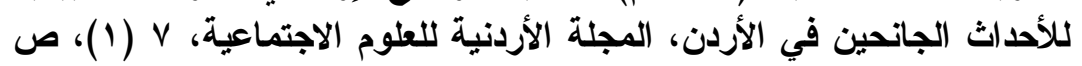

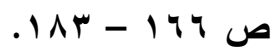

V V أشيفر، شارلز وميلمان، هوارد (919 ام). مشكلات الأطفال والمراهقين

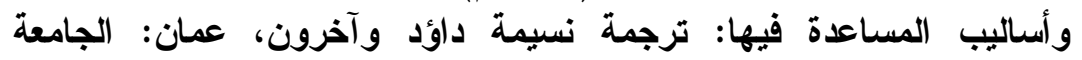

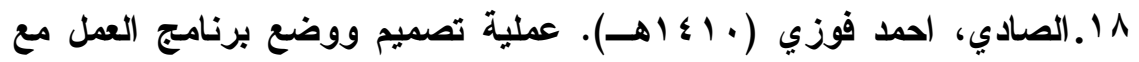

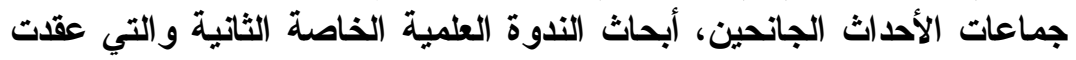

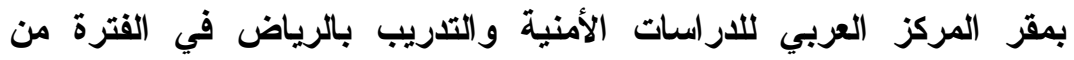

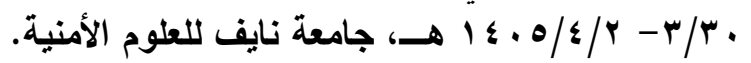

19.صبحي، سيد (r ..rم) الإنسان وصحته النفسية، القاهرة، الدار المصرية اللبنانية.

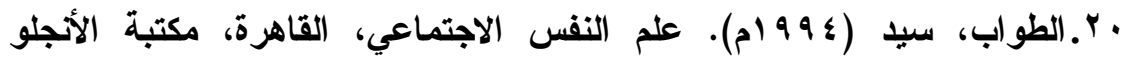

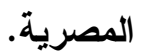




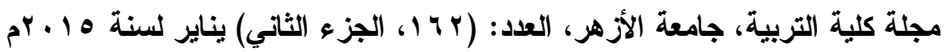

ا Y. عبد الغفار، عبد السلام (999 19). مقدمة في الصحة النفسية، القاهرة، دار

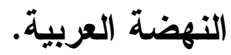

r Y.عبد الفتاح، غريب (999) علم الصحة النفسية، القاهرة، مكتبة الأنجلو

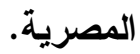

rr. عبد الله، عادل (. . . rم). العلاج المعرفي السلوكي، القاهرة: عربية للطباعة

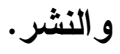

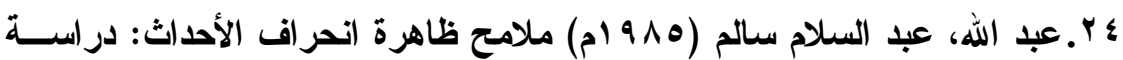

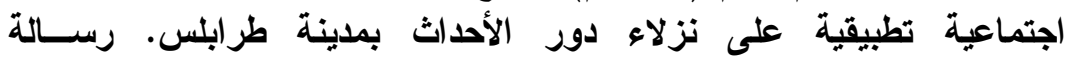

ماجستير (غير منشورة )، كلية التربية، جامعة لوعة الفاتح.

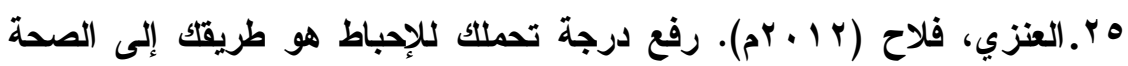

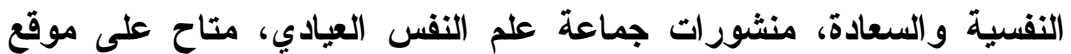

https://www.facebook.com/pages

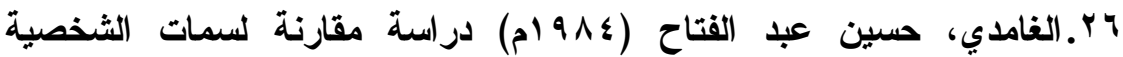

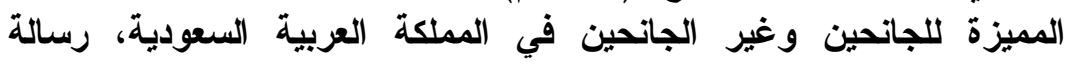
ماجستير (غير منشورة)، جامعة أم القرى. لمين

وV . فايد، حسين (ه . . بم) المشكلات النفسية الاجتماعية، القاهرة، دار طيبة للطبع

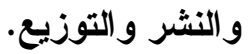

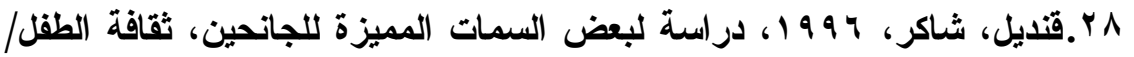

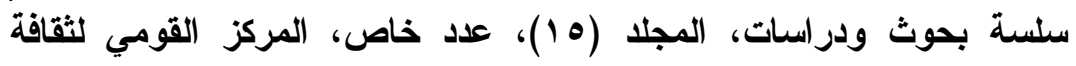

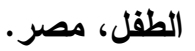

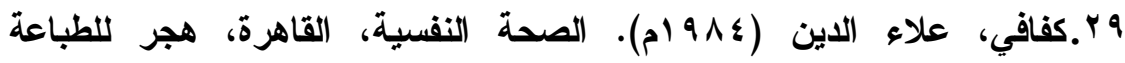
و التوزيع.

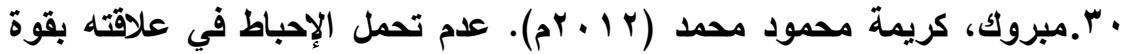

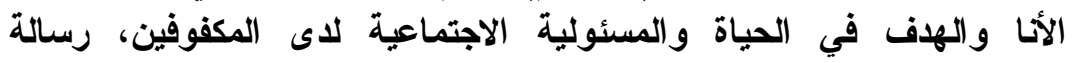
ماجستير (غير منشور)، قسم الصحة النفسية، كلية التربية - جامعة الفيوم.

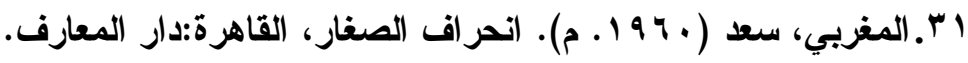

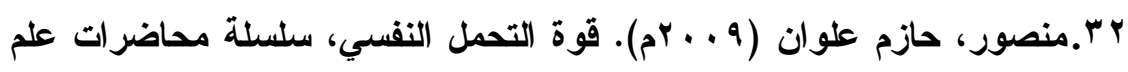

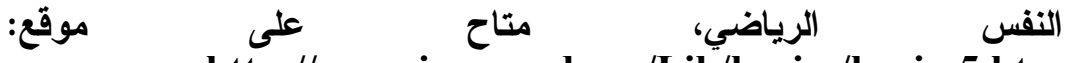
http://www.iraqacad.org/Lib/hazim/hazim5.htm 


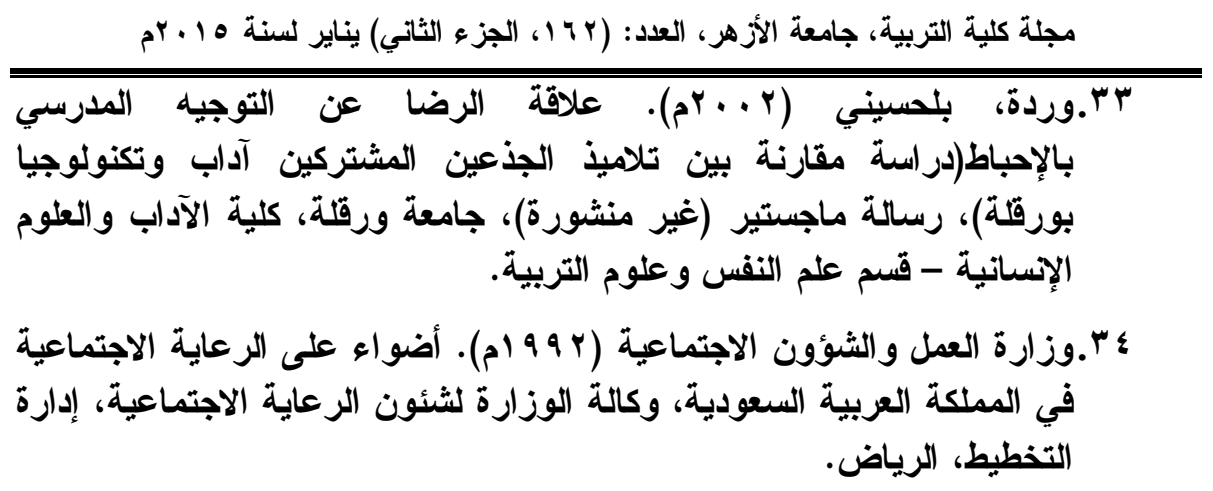

35. Anitei, Chraif \& Liliana, (2013). Influence of Fatigue on Impulsiveness, Aspiration Level, Performance Motivation and Frustration Tolerance Among Young Romanian Psychology Students, Procedia - Social and Behavioral Sciences, 78, May PP 630-634.

36. Baras, M. Y. ; Muller ,M. J. ; Gallhofer, B. \& Netter ,P. (2013). Relapse (number of detoxifications) in abstinent male alcoholdependent patients as related to personality traits and types of tolerance to frustration, Neuropsychobiology. ,67(4), May, PP241-8.

37. Beck, A. T. (1976). Cognitive Therapy and Emotional Disorders. New York: International University press.

38. Beck, K. H. ; Ali, B. \& Daughters ,S. B. (2014). Distress tolerance as a predictor of risky and aggressive driving, Traffic Inj Prev, 15(4), PP 349-54.

39. Chipea ,F. ; Negruti ，D. \& Trip ,S. (2012). Intercultural differences in frustration intolerance, Procedia - Social and Behavioral Sciences ,33, PP 583-587.

40. Coles, C. (2002). The relationship between personality, anger expression, and perceived family control among incarcerated male Juveniles. Journal of Adolescence.37 (146): 66.

41. Corey, G. (2005). Theory and Practice of Counseling and Psychotherapy. New York: Brooks/Cole.

42. Dragomir, G. ,Todorescu, L. L. \& Greculescu, A. (2011). Adolescents' Frustration Tolerance for Violence-Based Films, Procedia - Social and Behavioral Sciences ,30, PP 58-62. 
43. Dryden, W. (2014). Irrationalities Related to Low Frustration Tolerance or Short-Range Hedonism ,SMART Recovery Annual Conference,PP 26-28, Washington.

44. Ellis, A. (1977) Rational - Emotive Therapy. J.of The Counseling psychologist.7(1): 27.

45. Gulzar ,S. ; Yahya, F. ; Nauman, M. ; Mir, Z \& Mujahid, S. H. (2012). Frustration among University Students in Pakistan, International Research Journal of Social Sciences, 1(4), December, PP 7 - 15.

46. Handelman, D. R. (1981) The effects of A rational-Emotive education course on the rational beliefs, frustration tolerance and self- acceptance of high school student. PhD of education, Temple University Graduate Board.

47. Harrington, N. (2005). It's too difficult! Frustration intolerance beliefs and procrastination, Personality and Individual Differences ,39(5), October,PP 873-83.

48. Harrington, N. (2011). Frustration Intolerance: Thearapy Issues and Strategies. Journal of Rational - Emotive \& Cognitive - Behavior Therapy, 29, PP 4-16.

49. Hudley, C. (1992). Attributions for pride, anger, and guilt among incarcerated adolescents. Criminal Justice and Behavior, 19, PP 189-205.

50. Katherinehenning, (2014). How to Increase Low Frustration Tolerance, Available on line:http://understandingcbt.wordpress.com/2014/07/10

51. Ko ,C. H. ; Yen ,J. Y. ; Yen ,C. F. ; Chen, C. S. \& Wang ,S. Y. (2008). The association between Internet addiction and belief of frustration intolerance: the gender difference, Cyber psychol Behav,11(3), Jun, PP 273-8.

52. Lackey, S. (2014). REBT in Song: Lessons in Low Frustration Tolerance, Available at: http://albertellis.org/rebt-in-songlessons-in-low-frustration-tolerance/ 


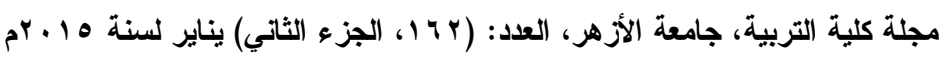

53. Lehnert,Overtholser\&Spirito ,(1994).Internalized and Externalized Anger in Adolescent Suicide Attempters ,Journal of Adolescent Research ,January 9(1),PP105-119,

54. Makarevich, O.F. (1986). Tolerance for frustration as a reliability factor in the work of the human operator, Kosm Biol Aviakosm Med, 20(5), PP24 - 26.

55. Nair, A. (2013). Helping Our Children Grow Their Frustration Tolerance, Available at: http://www.yummymummyclub.ca/blogs/andrea-nair-buttonpushing/20130423/helping-our-children-grow-their-frustrationtolerance

56. Ozer ,B. ; Demir ,A. \& Harrington, N. (2012)Psychometric properties of frustration discomfort scale A Turkish Sample, Psychological Reports: Measures \& Staistics, 111(1), PP $117-128$.

57. Pam, G. P. (2011) The Dallas REBT-CBT Meetup: Low Frustration Tolerance, Available at: http://www.meetup.com/The-Dallas-REBT-CBT-MeetupGroup/messages/boards/thread/10556727

58. Pouyamnesh, J. \& Firoozeh ,L. (2013). Compared the Learning Outcomes of Students with Math in High and Low Frustration Tolerance, Procedia - Social and Behavioral Sciences ,84 July, PP 837-40.

59. Sirota ,A. D. ; Rohsenow ,D. J. ; Dolan ,S. A. ; Martin, R. A. \& Kahler ,C. W. (2012). Intolerance for discomfort among smokers: Comparison of smoking-specific and non-specific measures to smoking history and patterns, Addictive Behaviors ,38 (3), March ,PP 1782-7.

60. Tripe, S. \& Bora, C. (2012). Psychometric properties of low frustration tolerance scale for students, Procedia - Social and Behavioral Sciences, 33, PP 578 - 582.

61. Winward,J. L. ; Bekman,N. M. ; Hanson,K. L. ; Lejuez, C. W. \& Brown ,S.A. (2014). Changes in emotional reactivity and distress tolerance among heavy drinking adolescents during sustained abstinence, Alcohol Clin Exp Res, 38(6) Jun, PP1761-9. 


\section{ملحق (1)}

النسخة العربية لمقياس عدم تحمل الإحباط

FDS (Harrington, 2005 )

$$
\begin{aligned}
& \text { ترجمة وإعادة تقنين } \\
& \text { د/ يوسف سطام العزي } \\
& \text { أستاذ علم النفس المساعد - جامعة تبوك }
\end{aligned}
$$

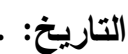

منطقة: . ............. م من

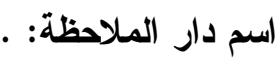

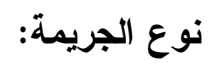

: النوع:

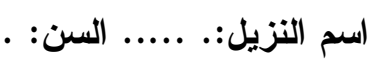

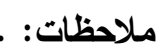

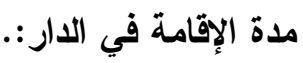

- - التعليمات: عزيزي المبحوث أمامك مجموعة من البنود تعكس حالتك عند مواجهة المواقف الإحباطية، اقرأ البند جيدا واختر بين فئات الإجابة، مع مراعاة الباة الإجابة

\begin{tabular}{|c|c|c|c|c|c|c|}
\hline |تنطبق & تنطبير & ت اتنطبق إلى & لا تنطبق & لا تنطبق & البند & P \\
\hline & & & & & أبحثث عن أسهل الحلول للمشكلة، فأنا لا أتحمل المشلة & 1 \\
\hline & & & & & الآن أتحمل الاتظظار للحصول على الأثياء التي أريدها & $r$ \\
\hline & & & & & 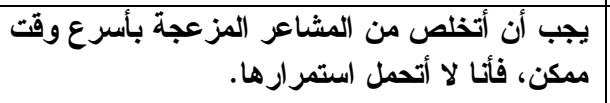 & $r$ \\
\hline & & & & & إمكاتيات. أنحمل أكون ممنوعا من إظهار كل ما لاي من & $\varepsilon$ \\
\hline & & & & & الصعوبة . استطيع اتجاز الأعمال التي تبدو أنها شديدة & 0 \\
\hline & & & & & لا أتحمل شعور إن الناس بعملون ضد أمنياتي. & 7 \\
\hline
\end{tabular}

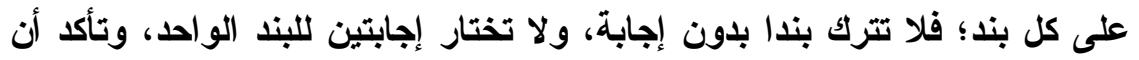
جميع إجاباتك وبياناتك سرية ولا تستخدم إلا لأغراض الإن البحث العلمي. 
مجلة كلية التربية، جامعة الأزهر، العدد: (r ا 1، الجزء الثاني) يناير لسنة ه 1 ـ بم

\begin{tabular}{|c|c|c|c|c|c|c|}
\hline تماما & كثيرا & |تطبق إلىى & لا تنطبق & لا تنطبق & 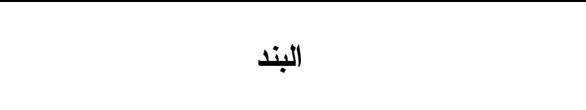 & م \\
\hline & & & & & لا أتحمل شعور أنتي افقد عقلي. & $\mathrm{V}$ \\
\hline & & & & & أهدافي. أتحمل الثعور بالإحباط نتيجة عدم تحقيق & $\Lambda$ \\
\hline & & & & & لا أستطيع اتجاز مهامي حينما يكون مزاجي غير & 9 \\
\hline & & & & & لا أتحمل شعور أن يقف الآخرين أمسام رغباتي. & 1. \\
\hline & & & & & لا أستطيع امتلاك أفكار دقيقة. & 11 \\
\hline & & & & & لي لا أتحمل خفض معاييري حتى ولو كان ذلك مفيدا & $1 \%$ \\
\hline & & & & & لا أتحمل الضغط على نفسي أثناء انجاز المهام & 14 \\
\hline & & & & & لا أحتمل أن ما يجرى لي أمر مفروغ منه. & $1 \leqslant$ \\
\hline & & & & & بالاستياء. أحتمل المواقف التي من الممكن أن اشعر فيها & 10 \\
\hline & & & & & لا أحتمل على إنهاء عمل غير راضي عنه تماما & 17 \\
\hline & & & & & لألأحتمل الضغط الناجم من الحاجة إلى انجاز & IV \\
\hline & & & & & لا أتحمل تلبية مطالب الناس الآخرين & 11 \\
\hline & & & & & لا أتحمل المشاعر المزعجة & 19 \\
\hline & & & & & لانجازه بشكل انجاز عمل إذ لم تكن لاى القدرة على & $r$. \\
\hline & & & & & لا أحتمل عمل الأشياء التي تسبب لي الإزعاج. & Y I \\
\hline & & & & & مخطئين. لا أحتمل تغيير موقفي عندما يكون الآخرين & rr \\
\hline & & & & & إذ لم تتثغل الألمور . لأدما في حياتي أوان أكون سعيدا & $r r$ \\
\hline & & & & & لا أتحمل الشعور بأنني لست الأكفأ بعملي & $r \leqslant$ \\
\hline & & & & & لا أحتمل الاستمرار في المهام غير الممتعة. & ro \\
\hline
\end{tabular}


مجلة كلية التربية، جامعة الأزهر، العدد: (r ا 1، الجزء الثاني) يناير لسنة ه 1 ـ بم

\begin{tabular}{|c|c|c|c|c|c|c|}
\hline تنطبق & كثيرا & تـنبق إلى & | لا تنطبق & لا تنطبق & البند & s \\
\hline & & & & & لا أحتمل الاتثقاد خصوصا حينما أكون على حق. & r \\
\hline & & & & & |لا أحتمل فقدان السيطرة علي مشـاعري & rv \\
\hline & & & & & |لا أحتمل أي هفوة في انضباطي لذاتي & YA \\
\hline
\end{tabular}

